\title{
Uncertainty in the determination of soil hydraulic parameters and its influence on the performance of two hydrological models of different complexity
}

\author{
G. Baroni ${ }^{1}$, A. Facchi ${ }^{1}$, C. Gandolfi ${ }^{1}$, B. Ortuani ${ }^{1}$, D. Horeschi ${ }^{2}$, and J. C. van Dam ${ }^{3}$ \\ ${ }^{1}$ Dipartimento di Ingegneria Agraria, Università degli Studi di Milano, Italy \\ ${ }^{2}$ Dipartimento di Ingegneria Idraulica, Ambientale, delle Infrastrutture Viarie e del Rilevamento, Politecnico di Milano, Italy \\ ${ }^{3}$ Department of Environmental Sciences, Wageningen University, The Netherlands
}

Received: 12 May 2009 - Published in Hydrol. Earth Syst. Sci. Discuss.: 4 June 2009

Revised: 26 January 2010 - Accepted: 27 January 2010 - Published: 9 February 2010

\begin{abstract}
Data of soil hydraulic properties forms often a limiting factor in unsaturated zone modelling, especially at the larger scales. Investigations for the hydraulic characterization of soils are time-consuming and costly, and the accuracy of the results obtained by the different methodologies is still debated. However, we may wonder how the uncertainty in soil hydraulic parameters relates to the uncertainty of the selected modelling approach. We performed an intensive monitoring study during the cropping season of a 10 ha maize field in Northern Italy. The data were used to: i) compare different methods for determining soil hydraulic parameters and ii) evaluate the effect of the uncertainty in these parameters on different variables (i.e. evapotranspiration, average water content in the root zone, flux at the bottom boundary of the root zone) simulated by two hydrological models of different complexity: SWAP, a widely used model of soil moisture dynamics in unsaturated soils based on Richards equation, and ALHyMUS, a conceptual model of the same dynamics based on a reservoir cascade scheme. We employed five direct and indirect methods to determine soil hydraulic parameters for each horizon of the experimental profile. Two methods were based on a parameter optimization of: a) laboratory measured retention and hydraulic conductivity data and b) field measured retention and hydraulic conductivity data. The remaining three methods were based on the application of widely used Pedo-Transfer Functions: c) Rawls and Brakensiek, d) HYPRES, and e) ROSETTA. Simulations were performed using meteorological, irrigation and crop data measured at the experimental site during the period June-October 2006. Results showed a wide range of soil hydraulic parameter values generated with the different
\end{abstract}

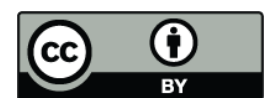

Correspondence to: G. Baroni (gabriele.baroni@email.it) methods, especially for the saturated hydraulic conductivity $K_{\text {sat }}$ and the shape parameter $\alpha$ of the van Genuchten curve. This is reflected in a variability of the modeling results which is, as expected, different for each model and each variable analysed. The variability of the simulated water content in the root zone and of the bottom flux for different soil hydraulic parameter sets is found to be often larger than the difference between modeling results of the two models using the same soil hydraulic parameter set. Also we found that a good agreement in simulated soil moisture patterns may occur even if evapotranspiration and percolation fluxes are significantly different. Therefore multiple output variables should be considered to test the performances of methods and models.

\section{Introduction}

Water retention and hydraulic conductivity curves are crucial input data in any modelling study on water flow and solute transport. Computed water balances are very sensitive to soil hydraulic parameters and therefore their accurate determination is essential to model hydrological processes (Jhorar et al., 2004). Moreover, at most sites soil hydraulic parameters are characterized by a strong variability in both vertical and horizontal directions. Therefore a large number of data are required to properly describe the hydraulic properties of an area.

Due to these facts, over the last decades many studies have been devoted to the development of methods for estimating soil hydraulic parameters. In general, two categories of methods can be distinguished: (1) measurement techniques and (2) predictive methods (Haverkamp et al., 2006).

Published by Copernicus Publications on behalf of the European Geosciences Union. 
The first techniques rely on precise experimental procedures that can be categorized as being either laboratory- or field-based. Laboratory methods are based on the accurate measurement of flow processes, but they are generally performed on small soil samples and as a result their representativeness of field conditions can be questioned. In addition, the presence of stones, fissures, fractures, tension cracks, root holes, as commonly encountered in unsaturated soil profiles, is difficult to be captured in small-scale laboratory samples. Field techniques can be more difficult to manage and control, but they offer the possibility to directly measure more representative soil hydraulic properties.

However, despite the progress that has been achieved, the measurement techniques remain time consuming and costly, especially when data are needed for large areas (Wösten et al., 2001). For this reason the definition of reliable methods for estimating soil hydraulic properties in areas where the amount of available information is limited remains a key issue. This explains why many attempts have been made at estimating soil hydraulic parameters by means of empirical relationships based on readily available soil data, such as textural soil properties and bulk density. These relationships, commonly referred as Pedo Transfer Functions (PTFs) (Bouma and van Lanen, 1987; Bouma, 1989), are particularly enticing as they are very well suited for large scale applications.

In general these relationships are based on statistical regression (e.g. Gupta and Larson, 1979; Rawls and Brakensiek, 1989; Cosby et al., 1984; Vereecken et al., 1989; Wösten et al., 1999; Saxton and Rawls, 2006), although some authors tried to develop more physically-based relationships (e.g. D'Urso and Basile, 1997). Some authors developed different approaches, like artificial neural networks (Minasny and McBratney, 2002; Schaap et al., 2001) or group methods of data handling (Pachepsky and Rawls, 1999), and promising results were obtained lately with support vector machines (Navin et al., 2009; Lamorski et al., 2008) and non-parametric pattern recognition tools (e.g. Nemes et al., 2006b, c). One of the advantage with these last methods is that the identification of an a priori relation between input and output data is not needed.

In spite of the wide application of these methodologies, the reliability of the results obtained is still under discussion (e.g. Tietje and Hennings, 1996; Romano, 1999). In most cases the methods are evaluated by comparing the values of selected soil hydraulic parameters obtained by the measurement techniques that are supposed to be more accurate with the indirectly estimated parameter values (Tietje and Tapkenhinrichs, 1993; Bastet et al., 1999; Nemes et al., 2003; Ungaro et al., 2005). These comparisons show that good performances can be obtained with predictive methods, but generally the results are site-specific. Therefore it is not possible to draw general conclusions about which methods are the best for a certain modeling purpose.
The direct comparison of parameter values does not provide information about their actual performance when used for specific applications, such as the simulation of soil moisture dynamics in agricultural fields. Therefore, rather than focussing on the direct comparison of parameter values, Wösten et al. (1986) proposed to use "functional criteria" directly related to specific applications. The basis for the identification of differences in hydraulic properties is determined by the accuracy with which the functional criteria are predicted and not by the accuracy with which hydraulic properties are characterized (Vereecken et al., 1992). Islam et al. (2006) compared a set of measured soil water content values with three different sets of simulated values, computed by the spatially distributed MIKE SHE model with three different sets of hydraulic parameters. They showed that the model provides reasonable estimates only if the soil hydraulic parameters are estimated by using PTFs developed for the soils of the area. However, they pointed out that the best estimation method is yet to be identified because none of the considered methods can simulate soil water content data with a sufficient accuracy. Nemes et al. (2006a) tested various PTFs with SWAP and analyzed their performance from multiple aspects. They underlined the importance of the choice of the PTF to be adopted, since it explains the main part of the variability in simulated water deficits. They demonstrated that the impact on the percolation at $1 \mathrm{~m}$ depth of the use of different PTFs was insignificant when the cumulative value at the end of the simulation period was considered, but was significant for the distribution of the percolation over the period. In Gijsman et al. (2003) eight methods for estimating hydraulic parameters were compared using the functional approach for the prediction of crop yield by the CROP-GRO-Soybean model. The authors showed that the discrepancy between estimations is so high that it is hard to make recommendations on which methods to use for which soils. Similar results were obtained by Soet and Stricker (2003) using a numerical Richards equation-based model, looking at the runoff/percolation generation, evapotranspiration and capillary rise. Cresswell and Paydar (2000) used the SWIM model with six different sets of hydraulic parameters. They showed that the error due to inaccurate hydraulic parameters tends not to be reflected in predicted soil water storage but instead in predicted drainage and evapotranspiration fluxes. This important result underlines that the use of profile water storage as the sole basis for functional comparison of methods may lead to misleading conclusions and that other water balance terms should also be taken into account. Vereecken et al. (1992) showed that the uncertainty in hydraulic parameters results in a considerable variation of simulated soil moisture supply capacity and of the downward flux below the root zone. Soil variance component analysis indicated that about $90 \%$ of the variability of the moisture supply capacity for a soil map unit was due to the estimated hydraulic parameters. This variability was larger than the with-in map-unit variability of soil properties. Similar 
results were shown by Christiaens and Feyen (2001). Guber et al. (2009) showed that good performances for soil water content can be obtained considering several PTFs (i.e. in their case 19) and using appropriate methods (i.e. equal weights, Bayesian model averaging, etc.) to combine the water moisture patterns predicted by using a Richards equation-based model with the different PTFs .

Workmann and Skaggs (1994) used two hydrological models of different complexity considering the uncertainty in the soil hydraulic parameter sets. Results pointed out that for the case study the model concept uncertainty was less important than parameters uncertainty. These findings motivate to further investigate under what circumstances the differences among modeling schemes are overwhelmed by uncertainty in the soil hydraulic parameters.

In spite of the large number of existing hydrological models, there are only two main approaches used for the mathematical representation of water flow in the unsaturated zone: numerical solutions of the Richards equation and reservoir cascade schemes. The Richards equation is the fundamental governing equation for the description of the flow in unsaturated porous media. Models based on its numerical solution were at first developed for the local scale and generally applied after a detailed calibration. Examples are SOIL (Johnson and Jansson, 1991), SWAP (van Dam et al., 1997), HYDRUS (Simunek et al., 1998). Nowadays, a number of physically based distributed-parameters models have become available, such as HydroGeoSphere (Sudicky et al., 2006), LGM-SWAP (Stoppelenburg et al., 2005), WaSiM (Schulla and Jasper, 2001), MIKE-SHE (Refsgaard and Storm, 1995). On the other hand, reservoir schemes have been adopted for decades in many hydrological models across scales, from field to global: EPIC (Sharpley and Williams, 1990), WEPP (Flanagan and Livingston, 1995), ANSWERS-2000 (Bouraoui and Dillaha, 1996), SWAT (Neitsch et al., 2002), UZF1 (Niswonger et al., 2006) are just few of the existing models. Due to the simplifications in the representation of the system, which very often makes them more comprehensible and manageable to non-expert final users, conceptual models are computationally efficient and stable. For these reasons they are still very attractive in many practical applications, such as large scale simulations, for which usually long time periods are considered and repeated simulations are required (e.g. scenario analysis).

To what extent, or under what conditions, the simpler reservoir models can capture the main features of water transfer dynamics in the unsaturated zone, at the local or at larger scales, is still an open question. A number of studies on models intercomparison have been conducted (e.g. Herbst et al., 2005; Eitzinger et al., 2004; Guswa et al., 2002; Maraux et al., 1998; Workmann and Skaggs, 1994), but rarely the effect of the uncertainty in model parameters or inputs has been taken into account in the analysis.
In order to further explore all these issues, in this study data collected in an intensive monitoring campaign were used to: i) compare five direct and indirect methods for deriving the values of soil hydraulic parameters and ii) evaluate the effect of the uncertainty in the determination of these parameters with respect to the resulting uncertainty in the outputs of two hydrological models of different complexity: SWAP (Kroes and van Dam, 2003) based on the numerical solution of the Richards equation, and ALHyMUS (Facchi et al., 2004; Gandolfi et al., 2006) based on a reservoir cascade scheme. Simulations were run for each model and each parameter set using inputs and crop parameters measured in a 10 ha maize field. Daily values of evapotranspiration, average soil water content in the root zone and water flux at the root zone bottom monitored in the field were used to test the performances of the methods to determine soil hydraulic parameters when used in the two hydrological models.

\section{Materials and methods}

\subsection{Experimental field site}

The monitoring activities were conducted during the cropping season 2006 in a 10 ha maize field located in Northern Italy (Landriano - PV), in the experimental farm A. Menozzi of the Agricultural Faculty of the State University of Milan $\left(45^{\circ} 19^{\prime} \mathrm{N}, 9^{\circ} 15^{\prime} \mathrm{E}, 88 \mathrm{~m}\right.$ a.s.l.).

Instruments for detailed monitoring of water and energy fluxes were installed in the experimental field in 2005. A micrometeorological eddy-covariance (EC) based station was located in the centre of the field. The station was equipped with: a 4-component radiometer (Kipp \& Zonen CNR-1), an infrared gas analyzer (LI-COR 7500) and a 3D sonic anemometer (Young RM-81000V). Soil heat flux monitoring by means of heat flux plates (Hukseflux HFP01) and soil thermocouples (ELSI) allowed to close the surface energy balance.

A vertical trench was dug close to the tower site to characterize the soil profile and to collect samples for standard soil analyses and undisturbed samples for laboratory retention and saturated hydraulic conductivity determinations. Five soil moisture sensors (Campbell Sci., CS616) and three tensiometers (SKYE) were installed in the profile at depths of $5,20,35,50,70 \mathrm{~cm}$ and 20, 35 and $70 \mathrm{~cm}$, respectively. Due to the presence of a shallow water table, $90-120 \mathrm{~cm}$ below the soil surface, a shallow piezometer with a pressure transducer device (STS) was installed as well. PAR (Photosintetically Active Radiation) sensors (LI-COR, LI190SB) completed the equipment. Standard meteorological devices, installed in a grass parcel located at $200 \mathrm{~m}$ distance from the experimental field, included a temperature and humidity sensor (Vaisala, HMP35C), a raingauge (LSI-Lastem, DQA), a global radiation sensor (LSI-Lastem, DPA) and a wind cup anemometer (WSD-1) installed at $2 \mathrm{~m}$ height. 
Table 1. Summary of the main data collected at the monitoring site (3 June-10 October 2006).

\begin{tabular}{ll}
\hline Cumulative rain & $429 \mathrm{~mm}$ \\
Mean temperature & $21^{\circ} \mathrm{C}$ \\
Crop & Zea Mays \\
Emergence & 6 June 2006 (DoY=157) \\
Harvesting & 10 October 2006 (DoY=283) \\
LAI $_{\max }$ & 4.2 \\
Crop height $_{\max }$ & $3.00 \mathrm{~m}$ \\
Rooting depth $_{\max }$ & $0.70 \mathrm{~m}$ \\
Sprinkler irrigation event & 8 June 2006 (DoY=159); $20 \mathrm{~mm}$ \\
Surface irrigation event & 14 July 2006 (DoY=195); $140 \mathrm{~mm}$ \\
Water table depth & 0.90-1.20 m \\
\hline
\end{tabular}

Spatially distributed measurements of leaf area index LAI (-), crop height $h_{c}(\mathrm{~m})$, and rooting depth $D_{r}(\mathrm{~m})$, were conducted periodically to characterize the crop in the field. Moreover, saturated hydraulic conductivity $K_{\text {sat }}\left(\mathrm{cm} \mathrm{h}^{-1}\right)$ was determined at depths of 20,35 and $70 \mathrm{~cm}$ by means of a Guelph permeameter.

During the cropping season 2006 there were two irrigation treatments: the first one on 8 June $(\mathrm{DoY}=159)$ with the sprinkler method to promote crop emergence, and the second one on 14 July (DoY=195) with the border method. The gross amount of water applied by the hose-raingun system during the first irrigation was controlled as carefully as possible during the operations, resulting in an average irrigation depth of $25 \mathrm{~mm}$. In order to confirm this amount, the measurements of the soil moisture sensors installed at different depths were used to derive the increase in soil moisture stocked in the profile after the irrigation. Only the values measured by the three upper probes showed significant changes and gave an estimated $20 \mathrm{~mm}$ increase in soil moisture. Taking into account the water losses before reaching the soil surface this value is in good agreement with the gross irrigation amount and it was therefore considered as the net irrigation supply at the soil surface.

At the second irrigation, the canal water discharge was monitored by an electromagnetic flow sensor (Nautilus OTT), yielding an irrigation amount of $140 \mathrm{~mm}$. The run-off was negligible in the entire monitoring period.

A summary of the main data collected at the monitoring site is shown in Table 1. Texture and organic matter measurements for the horizons identified in the soil profile are reported in Table 2.

\subsection{SWAP model}

The soil-water-atmosphere-plant (SWAP) model is a widely applied and well documented model, based on a finite difference solution of the Richards equation (van Dam et al., 1997). It simulates the vertical soil water flow and solute transport in close interaction with crop growth. Richards
Table 2. Chemical-physical data for the horizons of the experimental soil profile.

\begin{tabular}{lrrrr}
\hline Depth (cm) & $0-10$ & $10-40$ & $40-55$ & $55-90$ \\
\hline Horizons (USDA system) & Ap1 & Ap2 & B & 2 Bt1 \\
Sand (\%) & 67.0 & 65.0 & 56.0 & 44.5 \\
Silt (\%) & 30.5 & 32.0 & 39.5 & 31.5 \\
Clay (\%) & 2.5 & 3.0 & 4.5 & 24.0 \\
Organic matter (\%) & 2.7 & 2.3 & 1.9 & 0.5 \\
Bulk density $\left(\mathrm{g} \mathrm{cm}^{-3}\right)$ & 1.19 & 1.24 & 1.30 & 1.60 \\
\hline
\end{tabular}

equation (Richards, 1931) is applied to compute transient soil water flow:

$C(h) \frac{\partial h}{\partial t}=\frac{\partial}{\partial z}\left[K(h)\left(\frac{\partial h}{\partial z}+1\right)\right]-S_{a}$

where $C(h)\left(\mathrm{cm}^{-1}\right)$ is the differential soil water capacity $(\partial \theta / \partial h), \theta(-)$ is the volumetric water content, $h(\mathrm{~cm})$ the soil water pressure head, $K(h)\left(\mathrm{cm} \mathrm{d}^{-1}\right)$ the hydraulic conductivity, $S_{a}\left(\mathrm{~d}^{-1}\right)$ the root water extraction rate, and $z(\mathrm{~cm})$ the vertical coordinate (positive upward). The numerical solution of Eq. (1) is subjected to specified initial and boundary conditions, and requires known relationships between the soil hydraulic variables moisture $\theta$, pressure head $h$ and hydraulic conductivity $K$. The following relations between these variables were used (van Genuchten, 1980; Mualem, 1976):

$\theta(h)=\theta_{r}+\frac{\theta_{s}-\theta_{r}}{\left[1+|\alpha h|^{n}\right]^{m}}$
$K(\theta)=K_{\mathrm{sat}} S_{e}^{L}\left[1-\left(1-S_{e}^{\frac{1}{m}}\right)^{m}\right]^{2}$

where $\theta_{r}(-)$ is the residual water content, $\theta_{s}(-)$ the saturated water content, $S_{e}=\left(\theta-\theta_{r}\right) /\left(\theta_{s}-\theta_{r}\right)(-)$ the relative saturation, $\alpha\left(\mathrm{cm}^{-1}\right), n(-)$, and $m$ are empirical shape factors, $K_{\text {sat }}$ $\left(\mathrm{cm} \mathrm{h}^{-1}\right)$ the saturated hydraulic conductivity, and $L(-)$ an empirical coefficient. The value of $m$ is fixed as $m=1-1 / n$.

Canopy interception is calculated according to Braden (1985) as a function of the leaf area index (LAI). SWAP includes both a simple and detailed crop growth module. We used the simple crop module, in which crop growth is prescribed by LAI, crop height and rooting depth as functions of crop development stage. The potential evapotranspiration rate $\mathrm{ET}_{p}\left(\mathrm{~mm} \mathrm{~d}^{-1}\right)$ is estimated by the Penman-Monteith equation (Monteith, 1965; Allen et al., 1998). In field conditions where crops partly cover the soil, $\mathrm{ET}_{p}$ is partitioned into the potential soil evaporation $E_{p}$ $\left(\mathrm{mm} \mathrm{d}^{-1}\right)$ and the potential crop transpiration $T_{p}\left(\mathrm{~mm} \mathrm{~d}^{-1}\right)$ using the daily pattern of LAI (Goudriaan, 1977; Belmans et al., 1983). 


\subsection{ALHyMUS model}

The soil water model ALHyMUS (Facchi et al., 2004; Gandolfi et al., 2006) is based on a non-linear reservoir cascade scheme, including two reservoirs in the root-zone and one (or more) additional reservoir(s) extending from the root-zone to the groundwater table. The first reservoir represents the upper part of the soil profile in which infiltration, evaporation and percolation to the subsequent reservoir take place. The second reservoir extends through the root zone having a thickness variable with the phenology of the crop and considers the processes of transpiration and percolation to the reservoir beneath; in the last reservoir(s) only percolation is taken into account. The thickness of the last reservoir(s) may vary in time, depending on the fluctuations of phreatic levels.

Canopy interception is evaluated by the Braden formula (Braden, 1985). Evaporative and transpirative rates are computed using the FAO-56 dual crop coefficient method (Allen et al., 1998). A one-dimensional mathematical representation of the infiltration and percolation processes is adopted: the potential infiltration rate is estimated by the Green-Ampt equation (Green and Ampt, 1911); drainage discharges from each reservoir are determined using a simplified scheme, similar to those used in other conceptual models (e.g. ANSWERS-2000, Bouraoui and Dillaha, 1996; EPIC, Sharpley and Williams, 1990), which considers a Darciantype gravity flow; the relationship between the unsaturated hydraulic conductivity and the water content is modelled by Eq. (3). The influence of a shallow groundwater table is accounted for by the formula proposed by Liu et al. (2006), which gives the capillary rise $G_{c}\left(\mathrm{~mm} \mathrm{~d}^{-1}\right)$ from the groundwater surface to the transpirative reservoir as a function of the water content in the reservoir $\theta_{v}(-)$, the rate of potential evapotranspiration $\mathrm{ET}_{p}\left(\mathrm{~mm} \mathrm{~d}^{-1}\right)$ and the groundwater depth $D(\mathrm{~cm})$. Finally, all these terms are included in the daily water balance equations of the reservoirs, which are solved by an implicit iterative procedure.

\subsection{Soil hydraulic parameters}

Five different methods were used to estimate the soil hydraulic parameters $\theta_{s}, \theta_{r}, \alpha, n, L$ and $K_{\text {sat }}$ : parameter optimisation of retention and hydraulic conductivity data measured both in the laboratory and in the field, and three wellknown Pedo-Transfer Functions applied to commonly available field measurements of chemical-physical soil properties: Rawls and Brakensiek (1989), HYPRES (Wösten et al., 1999), ROSETTA (Schaap et al., 2001). The methods are coded in the text as LAB, f, RB, H and Ro respectively.

\subsubsection{Laboratory measurements}

Laboratory measurements were performed on undisturbed soil cores with diameter $d=7.5 \mathrm{~cm}$ and height $h=5 \mathrm{~cm}$ taken in replicate from each of the four soil horizons (total of eight cores). The samples were collected before tillage and related management activities took place on the bare soil. For each soil core, saturated hydraulic conductivity $K_{\text {sat }}\left(\mathrm{cm} \mathrm{h}^{-1}\right)$ was determined by the standard constant head technique (Reynolds et al., 2002). Soil water contents were measured for 13 matric pressure heads allowing drainage water retention characteristics to be determined from saturation to about $-300 \mathrm{~cm}$ using suction tables as described by Romano et al. (2002). Three additional points of the water retention function were measured with the pressure chamber method (corresponding to matric pressure head values of -3000 , -6000 and $-12000 \mathrm{~cm})$. The water retention function of van Genuchten (1980) was fitted to the measured $\theta-h$ values using the RETC code (van Genuchten et al., 1991). In the optimisation, $\theta_{s}$ values were fixed to those determined in the laboratory. The unsaturated hydraulic conductivity relationship was determined by using the water retention parameters plus the measured saturated hydraulic conductivity, according to the Mualem-van Genuchten model (van Genuchten, 1980).

\subsubsection{Field measurements}

Simultaneous field measurements of soil water content by soil moisture sensors and pressure head by tensiometers were collected in the experimental site at the depths of 20,35 and $70 \mathrm{~cm}$ during the monitoring period June-October 2006 . The water retention function of van Genuchten (1980) was fitted to the field measured $\theta-h$ values using the RETC code (van Genuchten et al., 1991). In the optimisation, $\theta_{s}$ values were fixed to those determined during the calibration of the CS probes, conducted in laboratory on samples collected in the summer 2006, after tillage activities. Saturated hydraulic conductivity $K_{\text {sat }}\left(\mathrm{cm} \mathrm{h}^{-1}\right)$ was measured by a Guelph permeameter at the same depths as the monitored $\theta-h$ values. As in the case of the laboratory measurements, the unsaturated hydraulic conductivity relationship was determined by using the water retention parameters plus the saturated hydraulic conductivity, according to the Mualemvan Genuchten model (van Genuchten, 1980).

No field measurements of pressure head were available for the $1 \mathrm{st}(0-10 \mathrm{~cm})$ and the $3 \mathrm{rd}(40-55 \mathrm{~cm})$ horizon of the soil profile (see Table 2). Due to this lack of data, we had to assume that the soil hydraulic parameters obtained by the measurements taken at $20 \mathrm{~cm}$ and $70 \mathrm{~cm}$ depth were representative of the 1 st and the 3rd horizon, respectively. This assumption shall be kept in mind when looking at the simulation results because, while the properties of the first two horizons are rather similar, there is a change to a more clayey texture at $55 \mathrm{~cm}$ depth (Table 2).

Finally, it seems to be important to point out that laboratory and field measurements were conducted in different periods. While the former were conducted during the winter season, the latter were carried out after tillage activities took place. In fact, all the instruments installed in the upper part of the profile (as far as $50 \mathrm{~cm}$ ) were removed before sowing 
(3 June 2006; DoY=154) to allow the mechanical operations to be carried out uniformly in the whole field. After this date the instruments were re-installed. The Guelph permeameter measurements of saturated hydraulic conductivity were also carried out during the cropping season.

\subsubsection{Pedo-Transfer functions}

Three widely used Pedo-Transfer Functions were applied to the texture and organic matter measurements available for the experimental profile (Table 2). The first one is the PTF of Rawls and Braekensiek (1989), based on non-linear multiple regression equations. Ungaro and Calzolari (2001) showed that these PTFs, even if based on US soils data base, have a good performance also for soils of the central Padana Plain (Northern Italy). The second PTF used is the so-called HYPRES (Wösten et al., 1999), derived by multiple regression techniques as well, but using a European data base of soils (although no soils of Northern Italy are included). The third PTF set used is ROSETTA (Schaap et al., 2001), developed by the United States Salinity Laboratory using a neural network, and based on US soil data.

The bulk density $\rho_{b}\left(\mathrm{~g} \mathrm{~cm}^{-3}\right)$ used in the PTFs was estimated from the organic matter OM (\%) values (Table 2) by the relationship proposed by Jeffrey et al. (1970), which showed to provide good results for the soils data of the area (ERSAL, 2001).

\subsection{Model inputs and parameters}

The models were run with the different sets of soil parameters for the period 6 June-10 October 2006 (DoY=157-283). Measured meteorological and irrigation data were used for the simulations. Daily values of crop height $h_{c}(\mathrm{~m})$, leaf area index LAI (-) and rooting depth $D_{r}(\mathrm{~m})$ were obtained by linear interpolation of the field data collected during the cropping season (Fig. 1). The daily pattern of basal crop coefficient $K_{\mathrm{cb}}(-)$ (Allen et al., 1998), used by ALHyMUS to compute the transpiration rate $T_{p}\left(\mathrm{~cm} \mathrm{~d}^{-1}\right)$, was estimated on the basis of literature values (Allen et al., 1998; Huygen et al., 1997; Borgarello et al., 1993) and adapted to the cropping stages observed in the field (Fig. 1). Table 3 shows the additional crop parameters needed for the implementation of the two models. Pressure head values $H_{\text {Lim1 }}-H_{\text {Lim5 }}(\mathrm{cm})$ for crop water stress conditions in SWAP are those proposed for maize in Hupet et al. (2004). The canopy resistance $r_{c}\left(\mathrm{~s} \mathrm{~m}^{-1}\right)$ for the SWAP Penman-Monteith equation is that proposed in literature for maize (Kroes and van Dam, 2003). Literature values were also adopted for $k(-)$, the extinction coefficient for global solar radiation, and $a\left(\mathrm{~mm} \mathrm{~d}^{-1}\right)$, an empiric parameter used in the interception equation (Braden, 1985). The value of $p(-)$, used by ALHyMUS to determine the fraction of Readily Avalilable Water (RAW) from the Total Available Water (TAW), is that proposed in Allen et al. (1998) for maize.

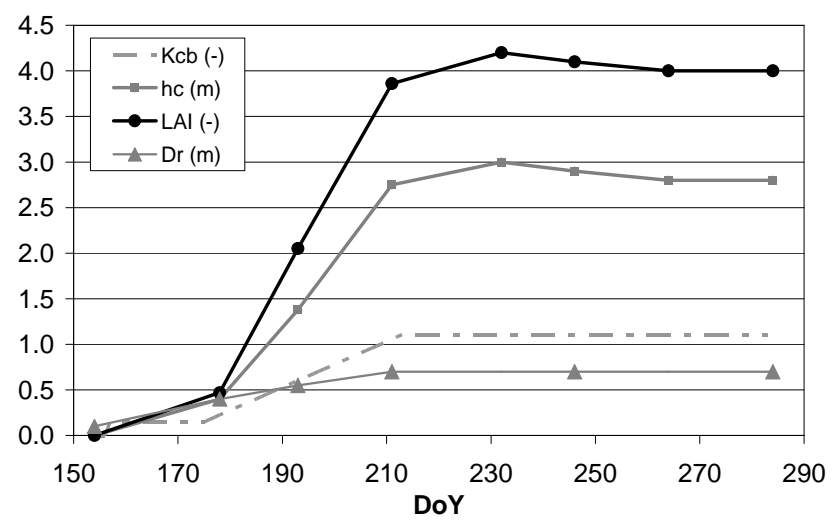

Fig. 1. Daily patterns of the following crop parameters: leaf area index LAI $\left(\mathrm{m}^{2} \mathrm{~m}^{-2}\right)$, root depth $D_{r}(\mathrm{~m})$, crop height $h_{c}(\mathrm{~m})$ and basal crop coefficient $K_{\mathrm{cb}}(-)$.

Soil moisture at field capacity $\theta_{\mathrm{FC}}(-)$ and at wilting point $\theta_{\text {WP }}(-)$ used by ALHyMUS to evaluate the Total Available Water (TAW) and the Total Evaporable Water (TEW) (Allen et al., 1998) were obtained for each horizon by Eq. (2), using pressure head values of $-100 \mathrm{~cm}$ and $-8000 \mathrm{~cm}$, respectively (Hupet et al., 2004).

The soil profile schematization adopted by the two models is illustrated in Fig. 2. For the SWAP model all the four soil horizons were taken into account, having the main properties listed in Table 2. Soil hydraulic parameters for each horizon were determined using the five methods illustrated above. ALHyMUS considers two reservoirs in cascade in the root-zone: for each reservoir soil hydraulic parameters were computed from those determined for each horizon. In particular, for all the parameters except for the saturated hydraulic conductivity, the arithmetic mean of the values of the soil hydraulic parameters of the horizons belonging to the reservoir, weighted by their thickness, was calculated. For the vertical saturated hydraulic conductivity the harmonic mean was computed (e.g. Freeze and Cherry, 1979). For the case study, a simplified approach for the parameterization of the second reservoir was adopted, i.e. fixing the soil hydraulic parameters for the whole simulation period at the value obtained considering the maximum extension of the root zone $(70 \mathrm{~cm})$. Thus, the parameters for the second reservoir didn't change over time with the roots' growth.

In both models the initial condition was set at the soil water content profile measured at the beginning of the simulation period. In particular, for SWAP the hydraulic heads corresponding to the measured soil water content values at different depths were calculated by inverting the van Genuchten equation for the different sets of soil hydraulic parameters; the obtained hydraulic head profiles were then used to set the initial condition. In ALHyMUS the soil moisture measures at different depths were considered to be representative of the soil water content for the layer surrounding the 
Table 3. Crop parameters values used by SWAP and ALHyMUS models (variables are explained in the text).

\begin{tabular}{ccccccccc}
\hline & \multicolumn{9}{c}{ SWAP } & & \multicolumn{2}{c}{ SWAP and ALHyMUS } & \multicolumn{2}{c}{ ALHyMUS } \\
$H_{\text {Lim } 1}(\mathrm{~cm})$ & $H_{\text {Lim } 2}(\mathrm{~cm})$ & $H_{\text {Lim } 3}(\mathrm{~cm})$ & $H_{\text {Llim } 4}(\mathrm{~cm})$ & $H_{\text {Lim5 }}(\mathrm{cm})$ & $r_{c}\left(\mathrm{~s} \mathrm{~m}^{-1}\right)$ & $a\left(\mathrm{~mm} \mathrm{~d}^{-1}\right)$ & $k(-)$ & $p(-)$ \\
\hline-10 & -40 & -325 & -600 & -8000 & 70 & 0.25 & 0.385 & 0.5 \\
\hline
\end{tabular}

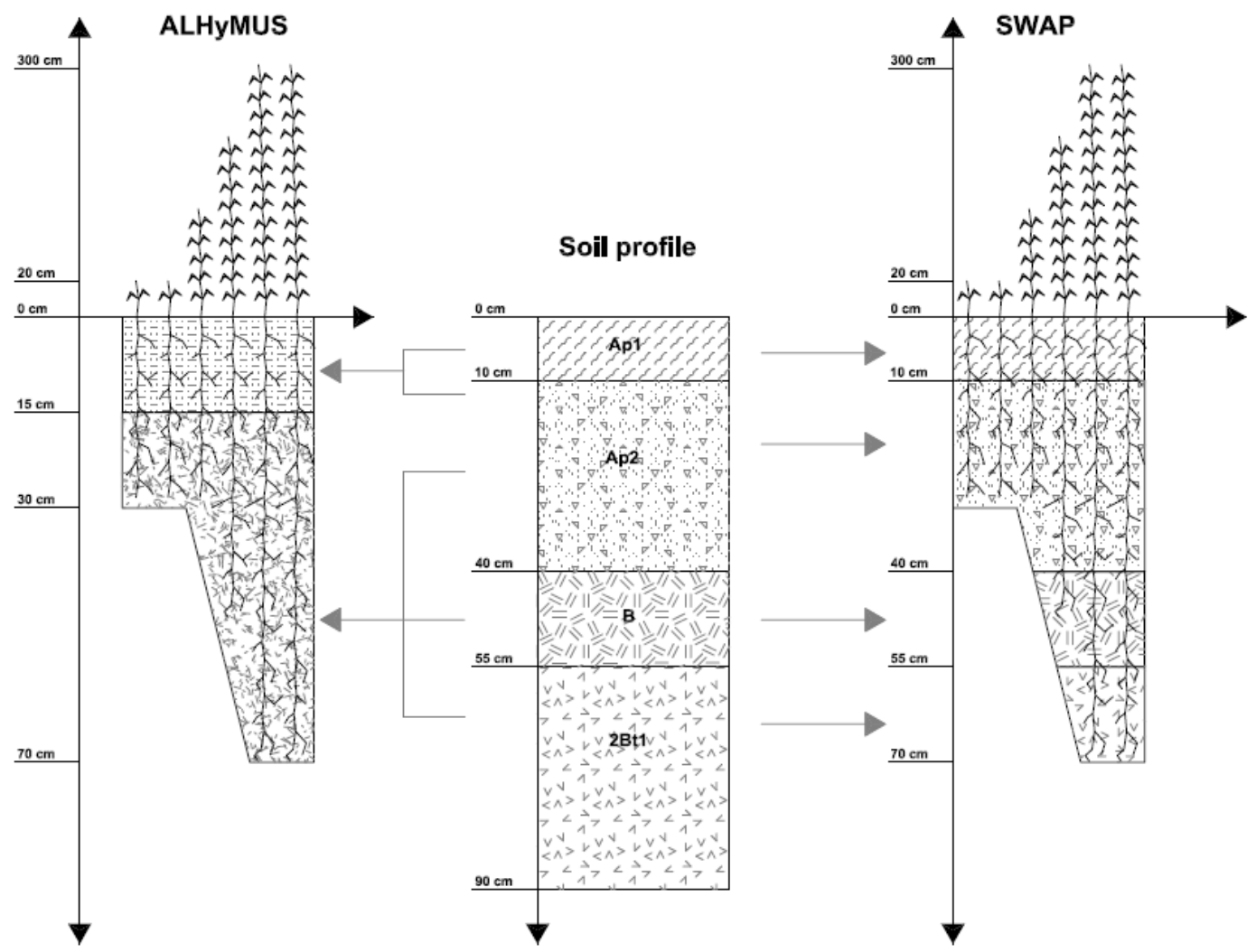

Fig. 2. Experimental soil profile and its schematization in ALHyMUS and SWAP models (the horizons are coded using the USDA system).

probe (i.e. extending above and below the probe for half the distance to the next probe). A weighted average was then performed to calculate the initial water content for the two reservoirs.

The bottom boundary condition was prescribed for both models according to daily measurements of groundwater table depth from the ground surface, which showed variations in the range $80-120 \mathrm{~cm}$ during the simulation period.

\subsection{Performance evaluation}

SWAP and ALHyMUS were implemented with the five different sets of soil hydraulic parameters described above resulting in a total of ten model-data sets, as summarized in Table 4. Daily measurements of evapotranspiration, average soil moisture in the root zone and flux at the root zone bottom collected in the field were used to test the performance of the five methods and of the two models. The statistical evaluation was carried out using the normalized root mean square error (NRMSE) and the mean error (ME) calculated from simulated and observed daily values for the period 6 June to 10 October 2006 (DoY=157-283) respectively as:

$\mathrm{NRMSE}=\frac{\mathrm{RMSE}}{\sigma}=\sqrt{\frac{\sum_{i=1}^{N}\left(s_{i}-m_{i}\right)^{2}}{\sum_{i=1}^{N}\left(m_{i}-\bar{m}\right)^{2}}}$

$\mathrm{ME}=\frac{1}{N} \sum_{i=1}^{N}\left(s_{i}-m_{i}\right)$

where $m_{i}$ are the measured values, $\bar{m}$ and $\sigma$ their mean and standard deviation, $s_{i}$ the simulated values, and $N$ is the number of data points. 
Table 4. Summary of the simulations carried out for the performance analysis.

\begin{tabular}{ll}
\hline Code & Description \\
\hline M & Measured values \\
S-Lab & SWAP with parameters from laboratory measurements \\
S-f & SWAP with parameters from field measurements \\
S-H & SWAP with parameters from the application of PTFs HYPRES \\
S-RB & SWAP with parameters from the application of PTFs of R\&B \\
S-Ro & SWAP with parameters from the application of PTFs Rosetta \\
A-Lab & ALHyMUS with parameters from laboratory measurements \\
A-f & ALHyMUS with parameters from field measurements \\
A-H & ALHyMUS with parameters from the application of PTFs HYPRES \\
A-RB & ALHyMUS with parameters from the application of PTFs of R\&B \\
A-Ro & ALHyMUS with parameters from the application of PTFs Rosetta \\
\hline
\end{tabular}

Table 5. Statistics for the soil hydraulic parameters determined using the five methods.

\begin{tabular}{llrrrrrrrr}
\hline Depth (cm) & & $\theta_{s}(-)$ & $\theta_{\mathrm{FC}}(-)$ & $\theta_{\mathrm{WP}}(-)$ & $\theta_{r}(-)$ & $n(-)$ & $\alpha g\left(\mathrm{~cm}^{-1}\right)$ & $K_{\mathrm{sat}}\left(\mathrm{cm} \mathrm{h}^{-1}\right)$ & $L(-)$ \\
\hline $0-10$ & mean & 0.49 & 0.28 & 0.07 & 0.03 & 1.402 & 0.050 & 5.8 & -0.187 \\
& \%CV & $12 \%$ & $16 \%$ & $18 \%$ & $10 \%$ & $3 \%$ & $72 \%$ & $89 \%$ & $-341 \%$ \\
\multirow{2}{*}{$10-40$} & mean & 0.45 & 0.28 & 0.09 & 0.03 & 1.351 & 0.057 & 5.5 & 0.162 \\
& $\% \mathrm{CV}$ & $12 \%$ & $14 \%$ & $28 \%$ & $7 \%$ & $7 \%$ & $91 \%$ & $77 \%$ & $338 \%$ \\
$40-55$ & mean & 0.42 & 0.29 & 0.08 & 0.03 & 1.448 & 0.029 & 2.6 & 0.049 \\
& \%CV & $18 \%$ & $12 \%$ & $14 \%$ & $9 \%$ & $7 \%$ & $98 \%$ & $79 \%$ & $1080 \%$ \\
$55-90$ & mean & 0.38 & 0.31 & 0.12 & 0.05 & 1.448 & 0.019 & 0.4 & -0.336 \\
& \%CV & $8 \%$ & $12 \%$ & $38 \%$ & $46 \%$ & $16 \%$ & $63 \%$ & $89 \%$ & $-386 \%$ \\
\hline
\end{tabular}

Simulation is perfect (i.e. $m_{i}=s_{i}$ ) if NRMSE is zero; predictions are worse than using the mean of observed values if NRMSE is greater than one. Simulation shows a systematic overestimation if ME is positive and a systematic underestimation if ME is negative.

The same indices were also used to compare pairs of simulations obtained running either the same model with two different parameter sets, or the two models with the same parameter set; in these cases $m_{i}$ and $\bar{m}$ were simulated values as well.

\section{Results and discussion}

\subsection{Comparison of soil hydraulic parameters}

Table 5 shows means and variations coefficient for the parameters determined using the five methods. Figure 3 illustrates the retention and the hydraulic conductivity functions at different depths obtained by introducing soil hydraulic parameters into the equations of van Genuchten (1980) and Mualem (1976) respectively.

There are different degrees of variation in the hydraulic parameters; such variation is exceptionally large for the saturated hydraulic conductivity $K_{\text {sat }}\left(\mathrm{cm} \mathrm{h}^{-1}\right)$ and for the shape parameter $\alpha\left(\mathrm{cm}^{-1}\right)$. The parameter $L(-)$ also shows a high variability but it is demonstrated that hydrological models are generally less sensitive to its variations (e.g. Jhorar et al., 2004).

Concerning the retention curves, PTFs RB in most of cases predict larger $\theta_{s}$ than the other methods. Due to relatively high $\alpha$ and $n$ values, causing a steep decline in the curve, the method nevertheless provides comparable or lower soil water contents $\theta$ for high suction values. Similar observations apply to $K_{\text {sat }}$ and to the unsaturated conductivity curve. Also in that case, due to the steepness of the curve, $K(\theta)$ values at higher suctions are comparable or even lower than those obtained by the other methods.

PTFs $\mathrm{H}$ result in lower $\theta_{s}$ and $K_{\text {sat }}$ than PTFs RB except for the deeper horizon; but the overall patterns of retention and unsaturated conductivity curves are similar to those predicted by the latter method. The curves generally show a more moderate and prolonged decline of water content and unsaturated conductivity with increasing suction.

The retention curves provided by PTFs Ro are generally characterized by lower values of $\theta_{s}$ and a shape similar to the curves predicted by PTFs $H$. The unsaturated conductivity curves are characterised by lower values of $K_{\text {sat }}$ compared to PTFs RB but, due to the shape parameters, $K(h)$ values are often higher than those obtained with the other methods. 


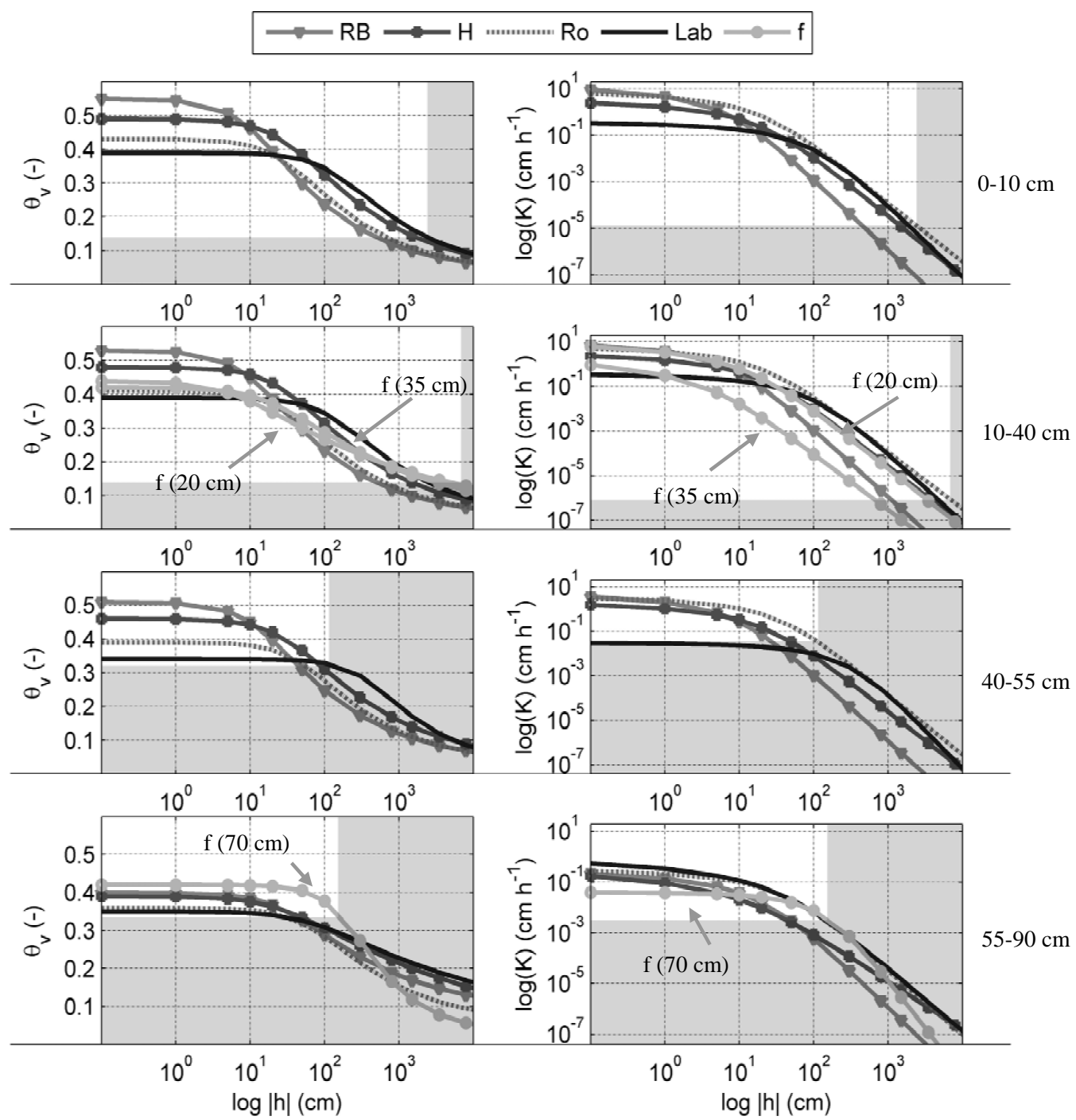

Fig. 3. Retention and hydraulic conductivity curves determined by using the five methods (for codes see Table 4) at the soil depths: 0-10 cm, $10-40 \mathrm{~cm}, 40-55 \mathrm{~cm}, 55-90 \mathrm{~cm}$. Drier water contents/pressure heads - not observed in the field during the monitoring period - are shaded in gray.

The retention curves derived from laboratory measurements of $h-\theta$ show smaller $\theta_{s}$ values than those given by other methods, but generally they are characterized by a more moderate and prolonged decline of water content with increasing suction, leading to more elevated water contents at higher pressure heads than the other methods. The laboratory $\theta_{s}$ values are even lower than the corresponding field values, which is usually uncommon to find in the literature (e.g. Pachepsky et al., 2004; Leij et al., 1996). In this particular case, it can be partially explained by the fact that the $\theta_{s}$ values of the field curves were actually determined in the laboratory, on samples collected immediately after tillage activities were conducted (see Sect. 2.4.2). The unsaturated conductivity curves determined by the laboratory measurements are characterised by smaller values of $K_{\text {sat }}$ in comparison with the other methods, except for the 4th layer for which the value is considerably higher. However, in all the layers the values of $K(h)$ at high suction values are generally higher then those obtained with the other methods. As for $\theta_{s}$ values, $K_{\text {sat }}$ values were determined in laboratory on samples collected before the soil tillage started.

The retention curves derived from field measurements of $h-\theta$ show values of $\theta_{s}$ within the range of those obtained with the other methods, but the behaviour of the curves is quite peculiar. In the 2 nd horizon, at the higher $h$ values, $\theta(h)$ values tend to become higher than those derived by applying the other methods, while for the 4th horizon the opposite occurs. The unsaturated conductivity curves based on the field measurements are characterised by smaller values of $K_{\text {sat }}$ in comparison with those obtained by the other methods; only for the 2nd horizon $K_{\text {sat }}$ values are higher than laboratory ones. For surface horizons the values of $K(h)$ remain lower 

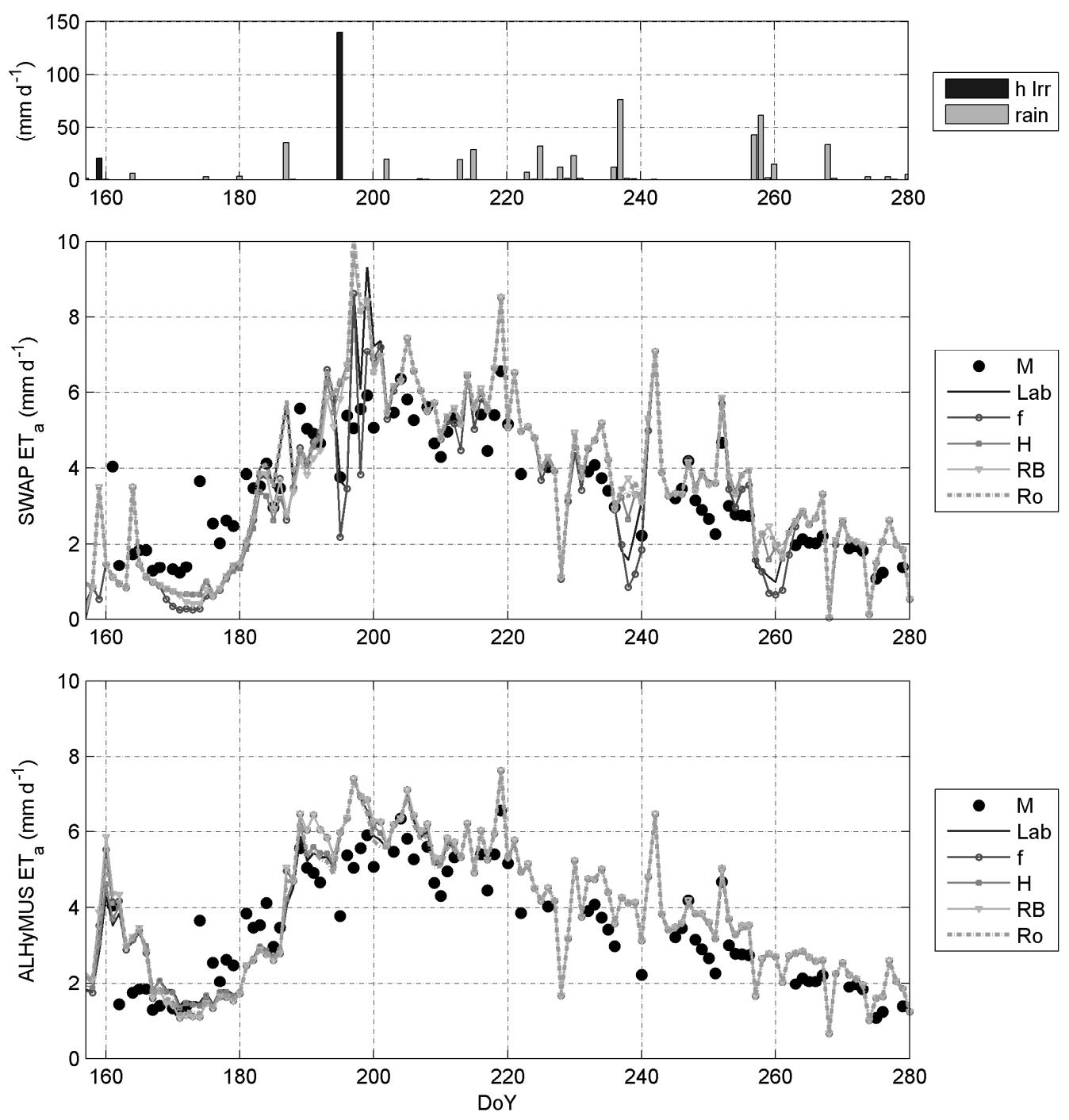

Fig. 4. Water inputs and evapotranspiration simulated by SWAP and ALHyMUS and measured by eddy-covariance (EC); for parameter sets codes see Table 4 .

than those predicted with the other methods for the whole range of $h$; for the 4th horizon $K(h)$ increases at higher suctions in comparison for example to PTFs RB. It's important to stress that since the soil water content in the field was always relatively high during the monitoring period - and this was particularly true for deeper layers due to the presence of the shallow groundwater table - at higher suctions the representativeness of the two curves obtained from the field data can be questioned.

Although the collected data are not enough to state it doubtlessly, the direct comparison between field and laboratory measurements suggested that a temporal variability in the soil hydraulic properties due to tillage practices could be present. Strudley et al. (2008) provided a detailed synopsis of the state-of-the-science for this issue and they argued that more investigations should be conducted, since only "enhanced data collection and measurement campaigns, combined with improved methods of parameter estimation and mechanistic incorporation within explicit spatiotemporal modelling frameworks should aid in the understanding of soil hydraulic behaviour due to tillage and related agricultural management."

\subsection{Performance evaluation}

\subsubsection{Evapotranspiration}

In irrigated fields actual evapotranspiration rate is generally very close to the potential rate. In this specific situation the soil hydraulic parameters are not influencing significantly the evapotranspiration flux, therefore the model outputs obtained with the different sets of parameter values are very similar (Fig. 4). All the outputs fit rather well with the EC evapotranspiration measurements and in all the cases the values 
of NRMSE are smaller then one. However, with all the soil hydraulic parameter sets and for both models, a systematic overestimation is shown (i.e. positive ME values in Fig. 9).

More insight can be achieved by splitting the cropping season into two periods. Simulation results for both SWAP and ALHyMUS show that the ratio of transpiration to evaporation increases rapidly starting from about DoY 175 till DoY 186. It can be noted that this period falls a few days before the main irrigation input occurs (between DoY 182 and DoY 195), when the soil is still relatively dry. Once these dates are reached, the agreement between measured and simulated ET starts improving. The simulation period was therefore split into a first part, where evaporation plays a major role, and a second one where transpiration is predominant.

Figure 5 shows the measured evapotranspiration values vs. the simulated values obtained with the two models implemented with the RB parameter set when the two periods are considered. Similar results were obtained implementing the models with the other sets of soil hydraulic parameters. In the first period when the crop is small and soil evaporation is more important than crop transpiration (approximately from the emergence to the beginning of July), the fitting is poor (NRMSE $=1.46$ and 1.41 respectively for SWAP and ALHyMUS). However, the systematic error in ALHyMUS is positive but small $\left(\mathrm{ME}=0.14 \mathrm{~mm} \mathrm{~d}^{-1}\right)$; on the contrary, SWAP underestimates the process $\left(\mathrm{ME}=-0.88 \mathrm{~mm} \mathrm{~d}^{-1}\right)$.

In this first period the soil characteristics of the upper portion of the profile (i.e. $10-15 \mathrm{~cm}$ ) and the water availability play the most important role in the determination of the evapotranspirative flux. The poor performance of the models is probably due to the presence of soil crusting and macroporosity, which were noticed in the field but are not accounted for in the two models. However, further research is needed to better investigate this issue.

Regarding the differences between the results of the two models, it can be noted that ALHyMUS calculates the actual evaporation rate using the FAO Penman-Monteith equation with the dual crop coefficient approach of Allen et al. (1998) on the basis of the soil water content of the first soil layer, while SWAP adopts the original Penman-Monteith equation and includes the procedure described in Kroes and van Dam (2003) to account for the limitations due to the water content in the upper portion of the soil profile. With these different setups generally ALHyMUS provides higher values of evapotranspiration rate than SWAP, as confirmed by an extensive simulation exercise carried out with the two models considering different soil types and a 13-years simulation period (results not shown in this paper).

In the second period (from DoY-184 to 283), transpiration is the dominant process and the model performances improve (NRMSE $=0.76$ and 0.59 respectively for SWAP and ALHyMUS with the PTFs RB). However, both models show a systematic overestimation of the evapotranspirative flux (ME $=0.68 \mathrm{~mm} \mathrm{~d}^{-1}$ and $0.66 \mathrm{~mm} \mathrm{~d}^{-1}$ respectively for SWAP and ALHyMUS). Different factors may have contributed to
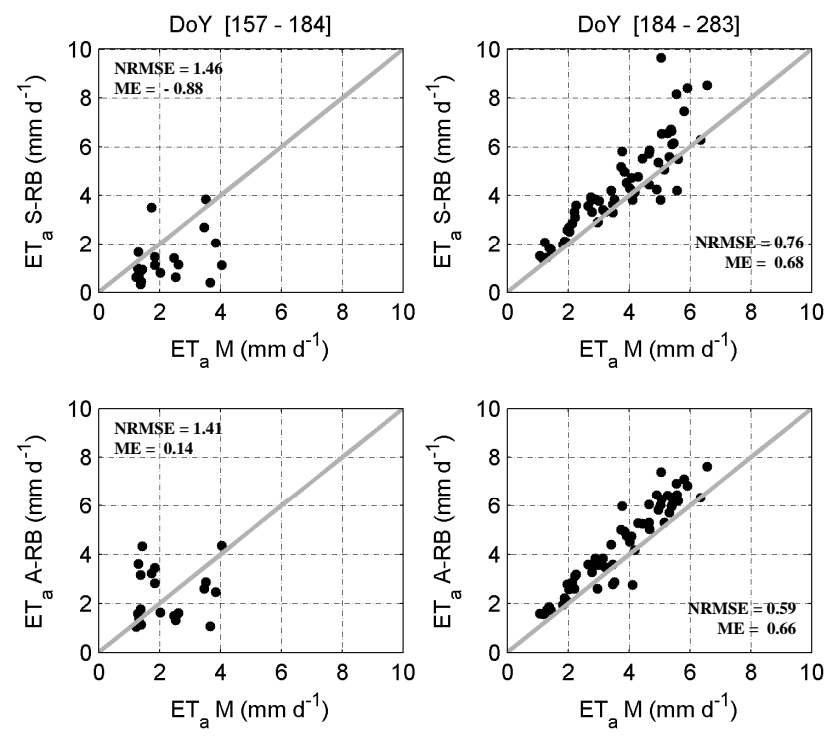

Fig. 5. Evapotranspiration measured by eddy-covariance (EC) and simulated by ALHyMUS and SWAP with the Rawls and Brakensiek parameter set (A-RB and S-RB respectively) for the period 3 June3 July and 3 July-10 October 2006.

these results, among which are the accuracy of crop parameter values and the actual environmental conditions. Indeed, while nutrients limitation or soil salinization can be excluded, recent investigations in the area (e.g. Gerosa et al., 2003) showed that atmospheric pollution can inhibit the transpiration process; in particular, high ozone concentrations lead to a general reduction of the productivity (average crop yield loss of 5\% for experiments conducted in open-top chambers) as well as to an increase of the crop sensitivity to other biotic and abiotic stresses.

A last consideration is that the SWAP results are highly variable after intense water inputs (e.g. days after the surface irrigation event: DoY=195 in Fig. 4). This behaviour is due to the different effects of the restriction to the transpiration flux, performed by SWAP when the soil water content is close to saturation, with the distinct parameter sets. Indeed, the limitation to transpiration is controlled by the pressure head thresholds $H_{\mathrm{Lim} 1}$ and $H_{\mathrm{Lim} 2}$, (see Table 3 ) and the same parameter values have clearly a different impact on the results depending on the set of soil hydraulic parameters considered.

\subsubsection{Soil water content}

The measurements of soil moisture contents by the five probes at $5,20,35,50$ and $70 \mathrm{~cm}$ depths were used to compute the average soil moisture contents in the root zone during the simulation period. The measurement of each probe was considered representative of the soil water content in the layer extending above and below the probe for half the distance to the next one. Then the daily average soil moisture 

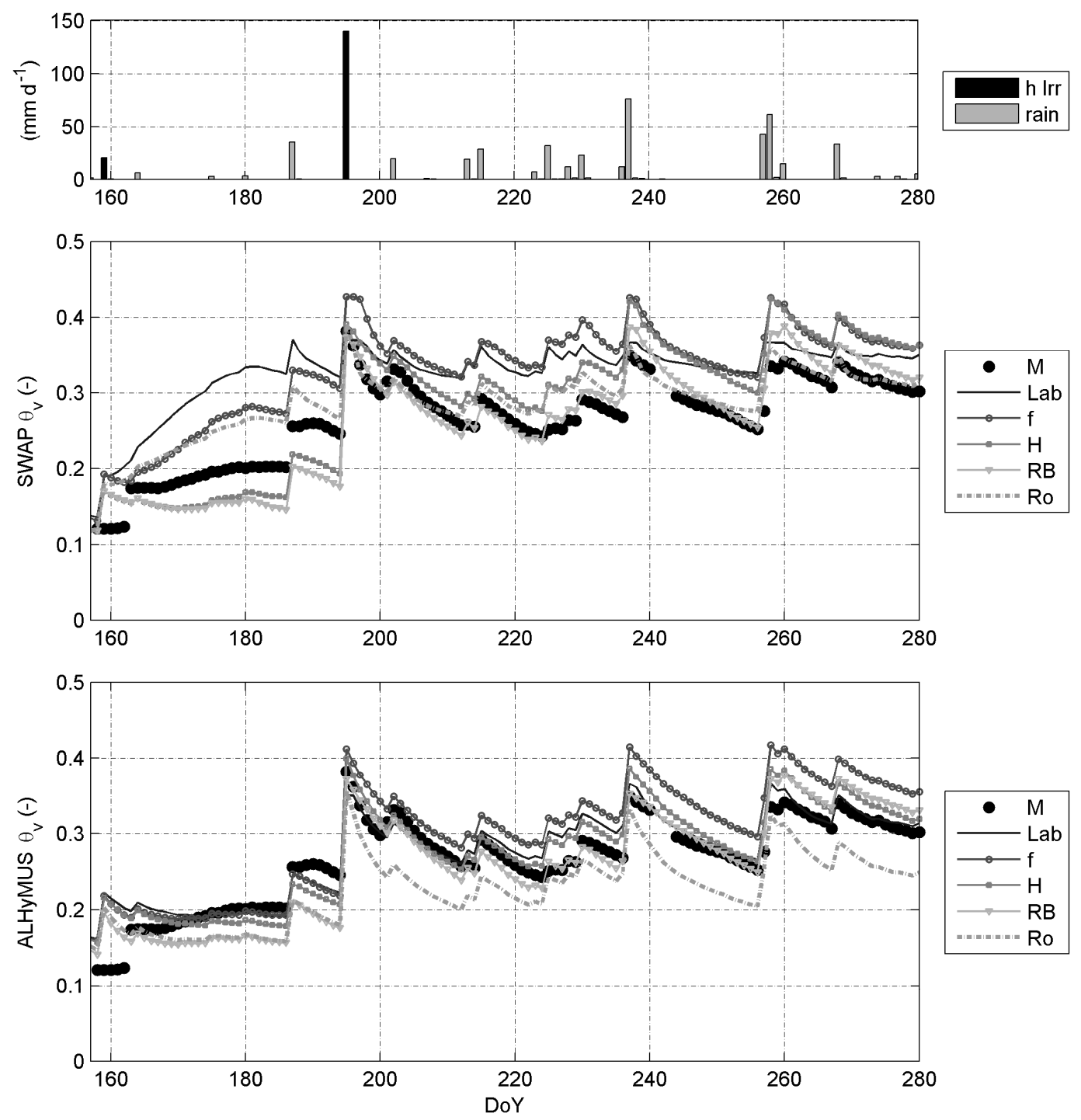

Fig. 6. Water inputs and average soil water content in the root zone simulated by SWAP and ALHyMUS and measured by soil moisture sensors; for parameter sets codes see Table 4.

content in the root zone was obtained by a weighted average of the measurements of the probes in the same day, where weights are proportional to the thickness of the layers. These average values, derived from measurements, will be simply indicated as measured values in the following.

The pattern of the simulated and measured values of the average soil moisture in the root zone and the corresponding efficiency indices are shown in Figs. 6 and 9, respectively. It can be noticed that both models show a high sensitivity to the different sets of hydraulic parameters. As documented in the literature (e.g. Coppola et al., 2009) both retention parameters and hydraulic conductivity parameters play a fundamental role in determining the soil water content evolution, the former being dominant during drainage processes and the latter during infiltration processes. This case study is further complicated by the presence of a shallow groundwater table which determines a water flux towards the root zone when the pressure head in proximity of the roots becomes particularly low.

Results also show that SWAP is highly sensitive to initial conditions (Fig. 6). The initial pressure head profile is in fact itself influenced by the set of hydraulic parameters used, since the head values were derive from the observed soil moistures through the retention curve. As a consequence, the soil moisture redistribution simulated by SWAP in the first period is itself an effect of the soil hydraulic parameterization. Figure 6 shows that with some simulations (namely $\mathrm{Lab}, \mathrm{f}$ and Ro) the upward fluxes from underneath the root zone, plus the $20 \mathrm{~mm}$ irrigation application in DoY 159, prevail on the evapotranspiration abstractions. The net water input is sufficient to progressively increase the simulated soil water content in the root zone, that is only $30 \mathrm{~cm}$ deep at this 
very early stage of plant growth, and the rate of growth of the soil water content in the three simulations is larger than rate of growth of the measured values in the whole period between the simulation start and DoY 180. The opposite occurs with $\mathrm{H}$ and $\mathrm{RB}$ simulations, where the upward gradients are smaller, due to the different shapes of the initial head profiles deriving from the $\mathrm{RB}$ and $\mathrm{H}$ retention curves: the upward fluxes from underneath the root zone are very close to the evapotranspiration abstractions and hence the simulated soil moisture contents are relatively stable during the interval DoY 165-185 and lower than measured ones.

The performances achieved are in some cases very good for both SWAP and ALHyMUS: NRMSE of 0.53 and 0.43 and ME of $-0.004\left(\mathrm{~m}^{3} \mathrm{~m}^{-3}\right)$ and $0.011\left(\mathrm{~m}^{3} \mathrm{~m}^{-3}\right)$ were found respectively with the parameter set of RB for the former model and of Lab for the latter. Average water contents simulated by SWAP show a good agreement with the observations also when the Ro parameter set is used, while ALHyMUS provides good results also with both $\mathrm{H}$ and $\mathrm{RB}$ parameter sets.

The range of variation of the two performance indices is quite large for both models (NRMSE 0.53 to 1.23 and ME -0.004 to 0.065 for SWAP; NRMSE 0.43 to 0.82 and ME -0.039 to 0.034 for ALHyMUS). Anyway, ALHyMUS proved to be less sensitive to the choice of the parameter set and provides values of NRMSE $<1$ in all cases.

It is worth observing that the performances of parameter sets derived by PTFs are similar to those of parameter sets obtained by direct methods. This is more evident in the case of the physically based SWAP model, for which values of NRMSE higher than one were obtained by both direct methods (Fig. 9). It is commonly accepted that when the model parameters can be calibrated on the basis of local observations of soil moisture and pressure head, then physically based models can provide better performances than conceptual models (e.g. van Dam et al., 2008; Coppola et al., 2009). Nevertheless, results of this study suggest that when the model parameters are derived from either direct or indirect methods, but no calibration is carried out, the performances of the two types of models can be quite similar. In the specific case study, ALHyMUS proved to be less sensitive to the parameter set and therefore to provide more homogeneous results compared to SWAP. These considerations seem to indicate that, without calibration, there is no clear predominance of physically based over conceptual models and the use of PTFs based on site-specific physico-chemical data could be a practical choice.

NRMSE and ME indices were computed also by coupling in all possible ways the results of the different simulations carried out with the two models, using either the same model with two different parameter sets, or the two models with the same parameter set. In particular, differences in the results provided by the two models with the same data set could be read as a measure of the uncertainty in the results attributable to the modelling approach.
To this end, Fig. 7 shows the average soil water content in the root zone simulated by SWAP and ALHyMUS respectively with the RB parameter set (which provides the best fitting between the two models) and the Ro parameter set (worst fitting).

The first two graphs in the left column of Fig. 10 show the NRMSE and ME indices of the simulations A-RB and SLab, S-f, S-H, S-Ro, relative to the S-RB simulation. The RB parameter set provides the best agreement between SWAP and ALHyMUS results, which are closer (in terms of both NRMSE and ME) than the different SWAP simulations.

The third and fourth graphs in the left column of the same figure show the NRMSE and ME indices of the simulations A-Ro and S-Lab, S-f, S-H, S-RB, relative to the S-Ro simulation. The Ro parameter set provides the worst agreement between SWAP and ALHyMUS results, and indeed both the NRMSE and ME values are worse for A-Ro than for the all the SWAP simulations, though the difference is not enormous.

Similar graphs, where the results of the S-Lab, S-f and S-H simulations are taken as reference patterns for NRMSE and ME computations, show an intermediate behaviour of these two indices, with an agreement of the SWAP and ALHyMUS simulations with the same parameter set often better than that of the SWAP simulations with the different parameter sets. Therefore, the analysis of the NRMSE and ME indices reveals that the range of within model variability, due to the choice of a different parameter set for a given model, is often wider than the range of inter-model variability, due to the choice of the model for a given parameter set.

\subsubsection{Bottom flux}

Figure 8 shows the comparison between the values simulated and "estimated from measurements" of the daily flux at the bottom of the root zone (whose depth increases from 30 to $70 \mathrm{~cm}$ during the crop growing stages, as shown in Fig. 1). The "estimated from measurements" values were obtained as residual terms of the daily hydrological balance computed by using the available measurements of soil water content and water inputs and outputs (i.e. rainfall, irrigation and evapotranspiration).

In the experimental site the bottom flow is significantly influenced by the shallow water table and thus the study period is characterized by an alternation of deep percolation and capillary rise. As for the soil water content, during infiltration events the simulated daily patterns are strongly influenced by the unsaturated hydraulic conductivity curves provided by the different methods; in all the remaining periods the contribution of retention parameters increases. For graphical reasons, Fig. 8 shows only the two most distant patterns, obtained respectively with the soil hydraulic parameter sets RB and Ro. The simulated patterns not shown in the figure lie mostly in between these two extremes (in particular: the simulated pattern obtained by PTFs $\mathrm{H}$ behaves similarly 

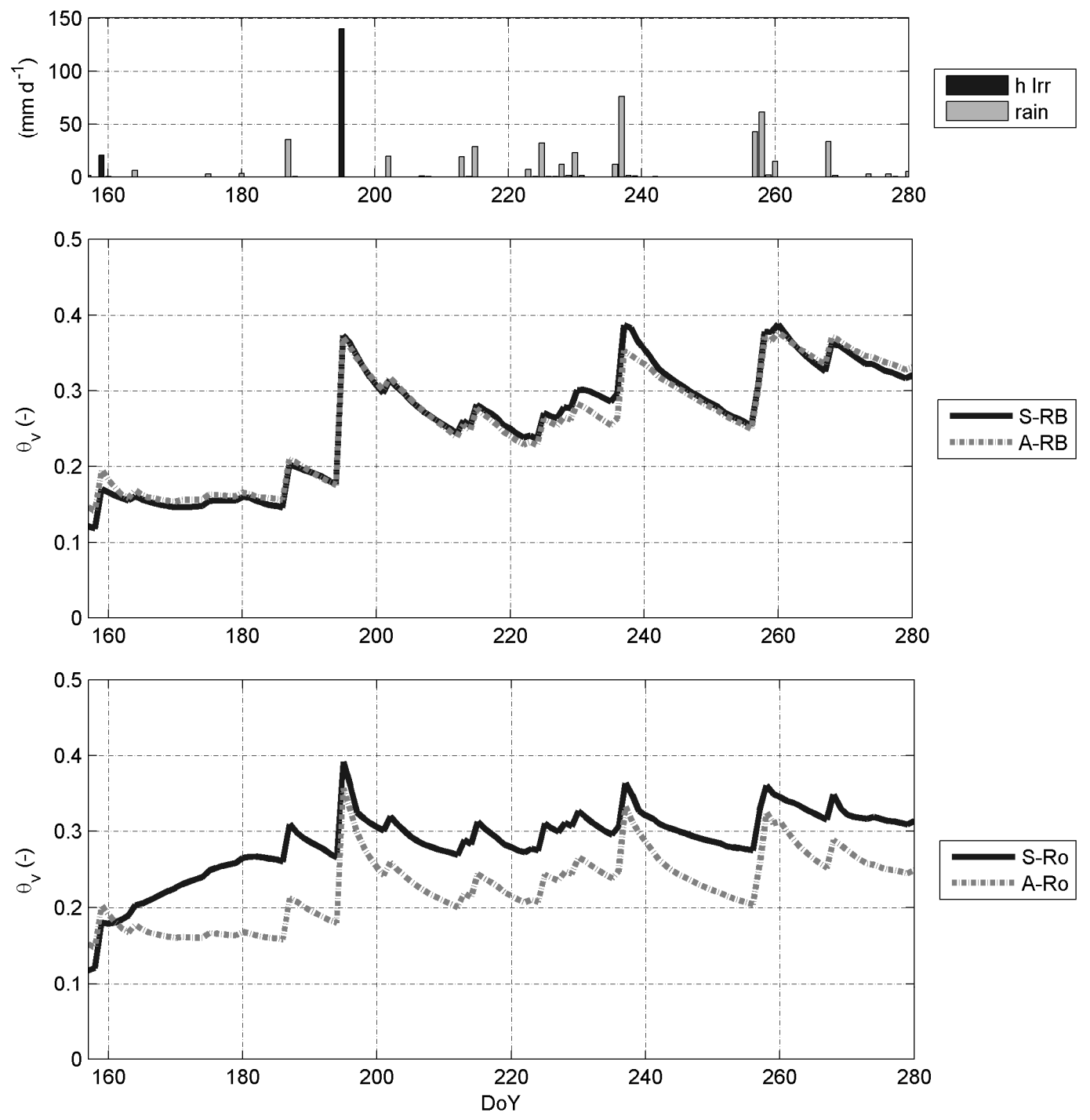

Fig. 7. Water inputs and average soil water content in the root zone simulated by SWAP and ALHyMUS with the Rawls and Brakensiek (RB) and Rosetta (Ro) parameter sets.

to the one corresponding to PTFs RB, the pattern obtained by using the Lab parameter set is close to the one provided by PTFs Ro, while the one corresponding to the field parameter set shows rather an intermediate behaviour). Figure 9 reports the values of the efficiency indices calculated for all days in the simulation period in which the value of the "estimated from measurements" flux is available.

Although the number of "estimated from measurements" values is rather limited, Fig. 8 shows clearly that both models succeed in capturing the general pattern of the bottom flux, but the overall performances are generally rather poor (i.e. NRMSE values between 0.6 and 1). As for the soil water content, it can be observed that SWAP shows a higher sensitivity to the choice of soil hydraulic parameters than ALHyMUS does.
The best performances in terms of NRMSE are achieved in SWAP with the field parameter set and in ALHyMUS with the Ro parameter set, although the fluxes seem to be underestimated also in these cases (negative ME values). Figure 8 shows that the highest percolation values during the infiltration events are achieved, with both models, when the PTFs Ro are adopted. The reason of that was found, as in Soet and Stricker (2003), in the relatively flat shape of the $K(\theta)$ curves near the saturation point, rather than to high values of $K_{\text {sat }}$. In all the other cases the simulated flux pattern turns out to be more delayed and smoothened. This is particularly true when the PTFs RB are adopted. The unsaturated conductivity curves obtained with this parameter set are in fact characterized by generally high $K_{\text {sat }}$ values, but also by a rapid decrease at increasing $h$ values (see Fig. 3). 

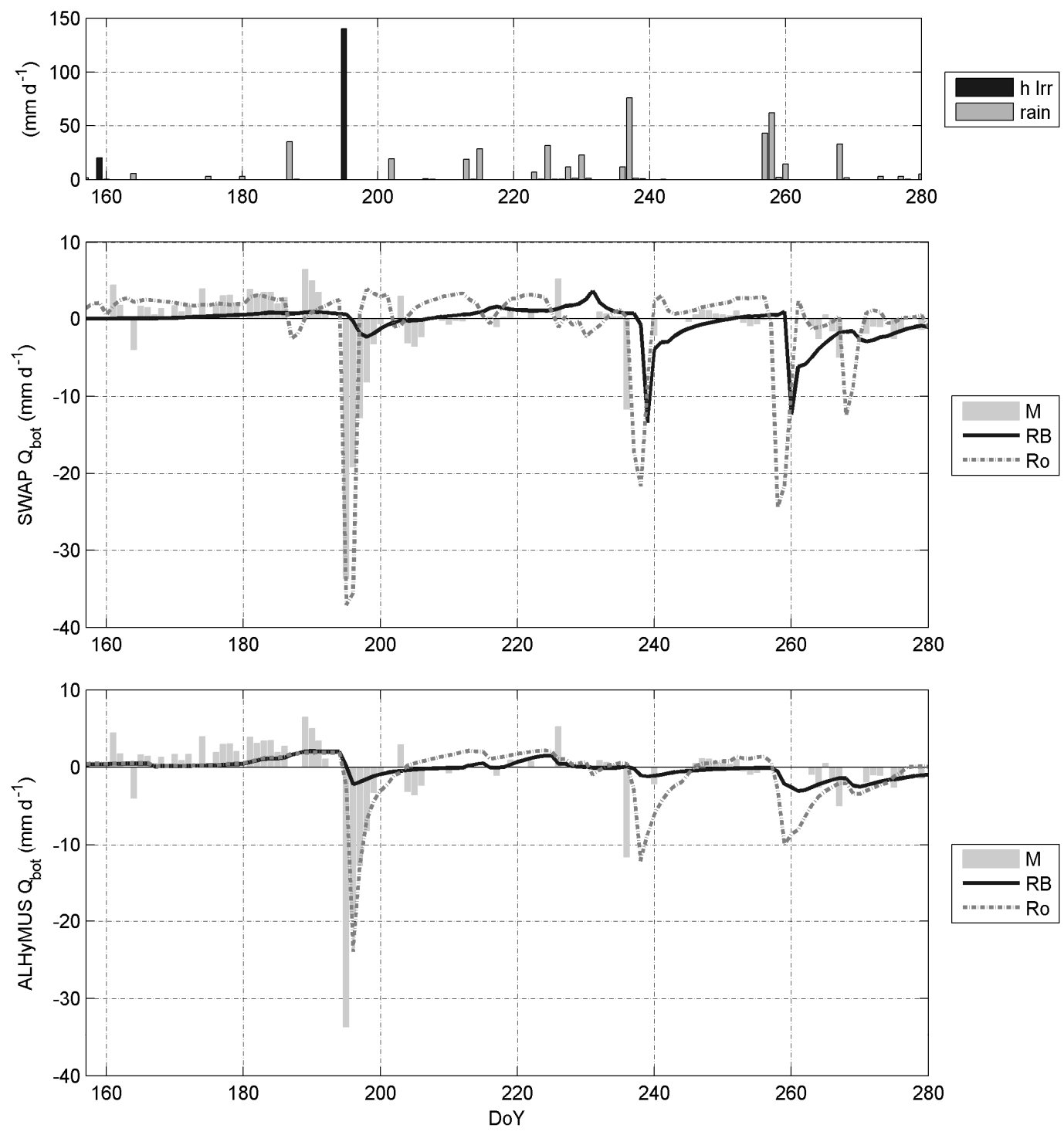

Fig. 8. Water inputs and flow at the bottom of the root zone simulated by SWAP and ALHyMUS and estimated by hydrological balance (M); for graphical reasons only results obtained with RB and Ro parameter sets are shown.

When looking at the percolation outflow at the bottom of the profile simulated by ALHyMUS, the effects of smoothing and delaying of the inputs can be seen clearly (Fig. 8). This behaviour was already reported in literature for cascade reservoir models (e.g. Gandolfi et al., 2006) and it is a consequence of the simplified description of some of the processes, such as the percolation (i.e. unit gradient assumption). However, looking at the patterns reported in Fig. 8 as well as at the NRMSE and ME indices, it cannot be concluded that ALHyMUS generally performs worse than SWAP, the results depend greatly on the parameter set adopted.

As for soil water contents in the profile, NRMSE and ME were also computed for fluxes at the bottom of the profile by comparing the results obtained by the different parameter sets and simulation models in all possible ways. The right column in Fig. 10 shows the NRMSE and ME indices calculated considering the daily fluxes at the bottom of the root zone simulated by SWAP respectively with the PTFs RB and Ro, and those simulated by both ALHyMUS with the same parameter sets and by SWAP with further parameter sets. Computed indices reveal that, also in the case of the bottom flux, the range of within model variability, due to the choice of different parameter sets for a given model, is often wider than the range of inter-model variability, due to the choice of the model for a given parameter set. 


$\square$ Lab $\square$ f $\square$ H $\square$ RB $\square$ Ro
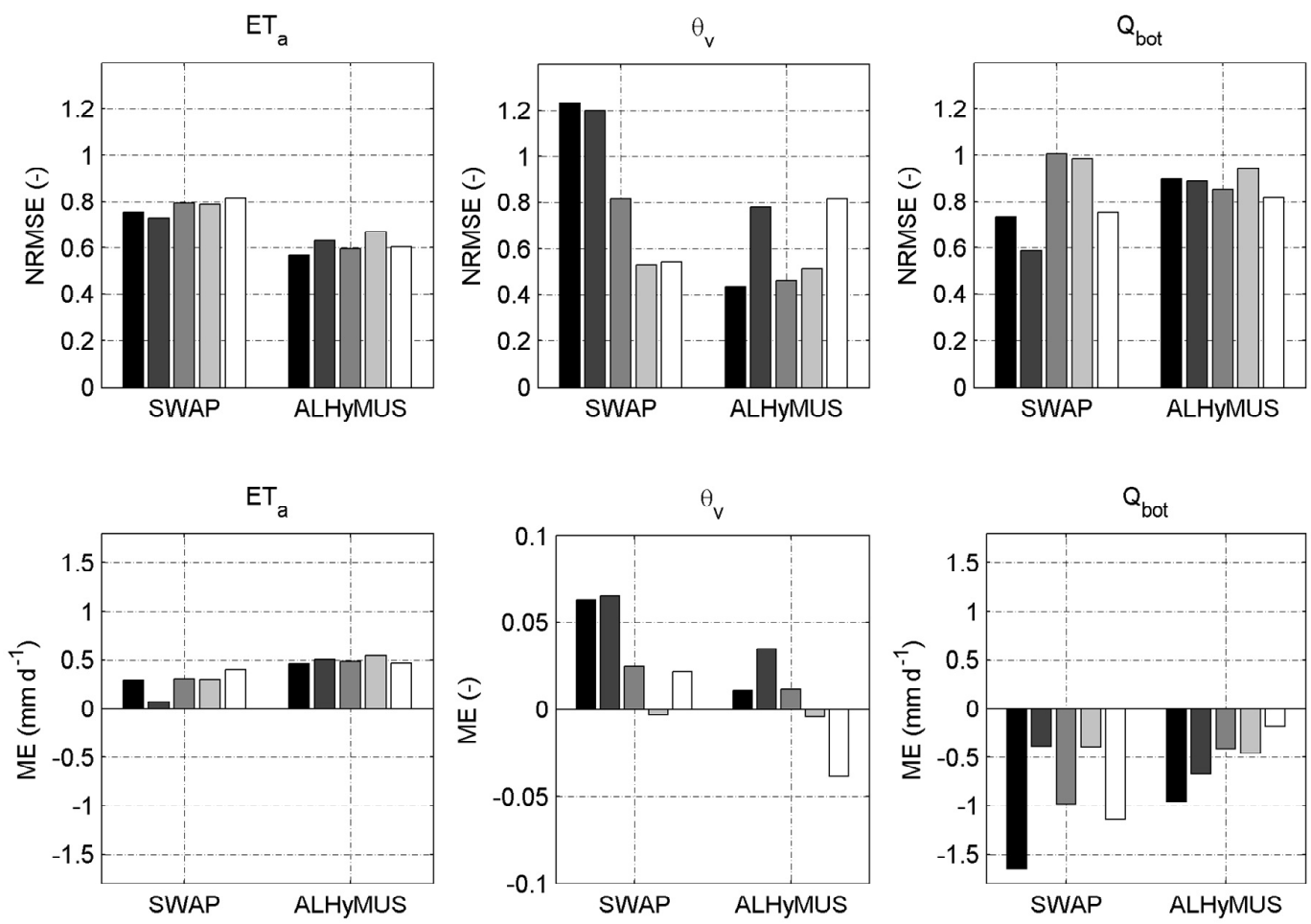

Fig. 9. NRMSE and ME indices for evapotranspiration, average soil water content in the root zone and bottom flux outputs (simulated vs. measured values); for parameter sets codes see Table 4 .

\section{Summary and conclusions}

This article investigates the uncertainty in modelling root zone water dynamics using two models of different complexity, SWAP, a Richards solver and ALHyMUS, a model based on a reservoir cascade scheme, in combination with Mualemvan Genuchten parameters determined by: i) parameter optimization using laboratory measured data, ii) parameter optimization using field measured data, iii) PTFs of Rawls and Brakensiek (1989), iv) PTFs of HYPRES and v) PTFs of ROSETTA. Performance of the models was tested by the normalized root mean square error (NRMSE) and the mean error (ME) calculated from simulated and observed daily values of evapotranspiration, average root zone soil moisture content, and flux across the bottom of the root zone. The same indices were also computed by combining in all possible ways the results of the different simulations carried out with the two models, obtained running either the same model with two different parameter sets, or the two models with the same parameter set. Data used for this research were collected during an intensive monitoring campaign at a 10 ha maize field located in Northern Italy, in the period June-October 2006.

The results show a high variability of the soil hydraulic parameter values in the different sets, especially in case of the saturated hydraulic conductivity $K_{\text {sat }}\left(\mathrm{cm} \mathrm{h}^{-1}\right)$ and of the shape parameter $\alpha\left(\mathrm{cm}^{-1}\right)$. Despite of this variability, the evapotranspiration fluxes simulated by the two models with the different sets of parameters are very similar. The reason for this is that when the actual evapotranspiration rate is close to the potential rate, as in the irrigated soil monitored in the study, soil hydraulic parameters play a minor role in the evapotranspiration process. For the analysis of the evapotranspiration fluxes the study period was split in two subintervals. In the first one, the evaporation process is predominant over transpiration and the performance of both models is quite poor, showing a general underestimation of the evapotranspiration flux. This could be due to the occurrence of soil crusting, noticed in the field but not accounted for in the two models. In the second period the transpiration process is prevailing and the quality of the simulations improves, though both models show a slight overestimation of the evapotranspiration. This might be due to non-optimal choice of crop parameters or to the occurrence of environmental stress factors, not taken into account in the simulations. The differences between the results of the two models are larger in the days immediately after intense water inputs; this is mostly due to the limitation of the transpiration flux simulated by SWAP when the soil conditions are extremely wet, which is not considered in ALHyMUS. 

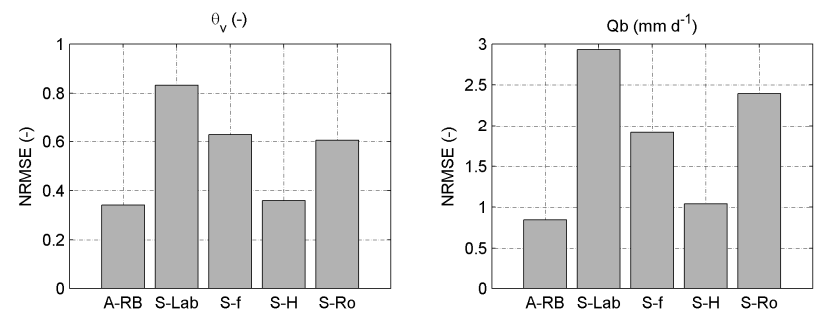

$\theta^{\prime}(-)$

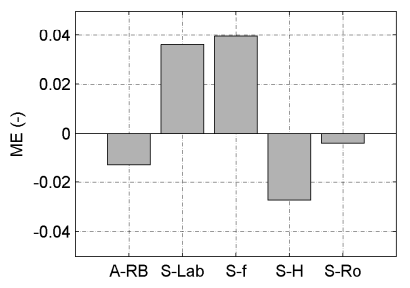

$\theta_{v}(-)$

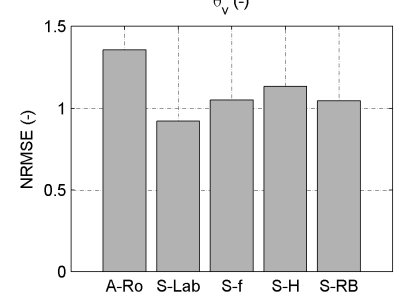

$\theta_{v}(-)$
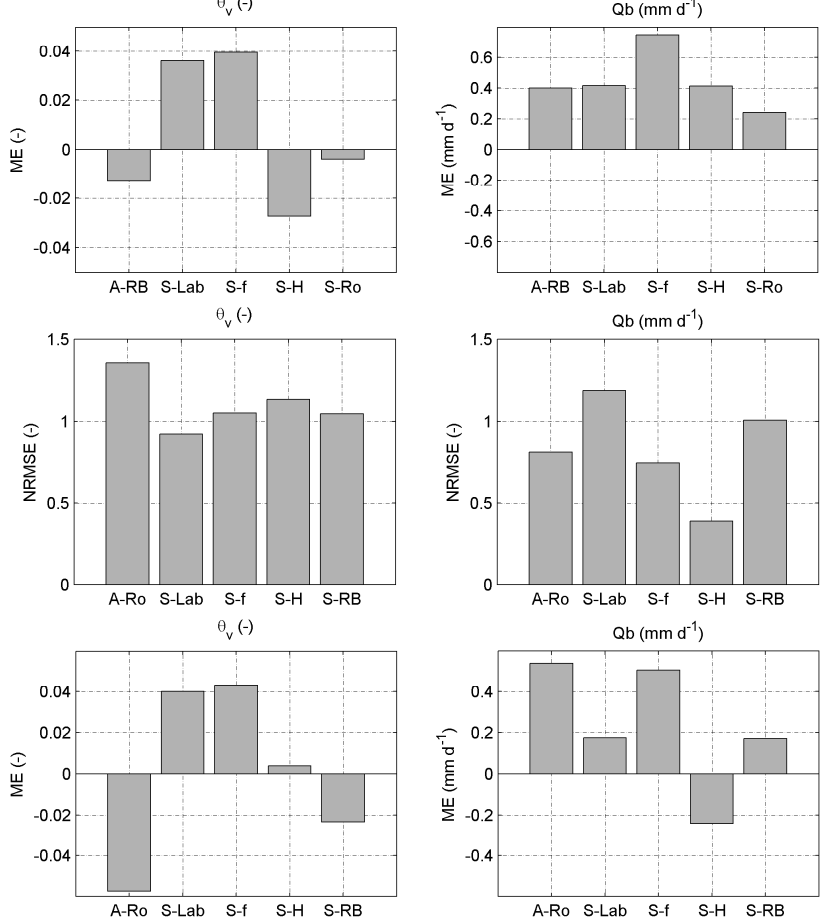

$\mathrm{Qb}\left(\mathrm{mm} \mathrm{d}^{-1}\right)$

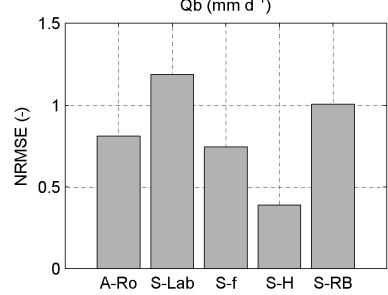
$\mathrm{Qb}\left(\mathrm{mm} \mathrm{d}^{-1}\right)$

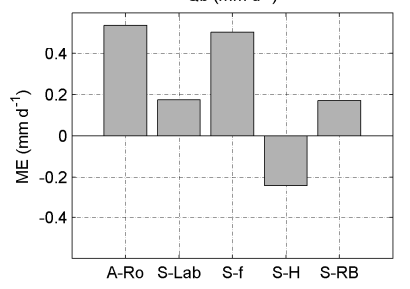

Fig. 10. NRMSE and ME indices for the soil water content (1st column) and the bottom flux (2nd column) provided either using the two models ( $S$ or $A$ ) with the same parameter set or the same model with two different parameter sets. The reference patterns are those simulated by SWAP respectively adopting the PTFs RB (1st and 2nd rows) and Ro (3rd and 4th rows).

Both models show a high sensitivity to the choice of the set of soil hydraulic parameters when the average soil water content in the root zone and the flux at its bottom are considered. However, ALHyMUS proved to be less sensitive to the choice of parameter set and therefore provides more homogeneous results compared to SWAP.

When looking at the soil water content, both models replicate quite well the time pattern of observed soil moisture, though SWAP simulations show a systematic overestimation of soil moisture. The best performances are achieved for both SWAP and ALHyMUS with sets of hydraulic parameters obtained with indirect methods (PTFs), even if not necessarily the same set for the two models. Good results for ALHyMUS are also achieved with the parameter set obtained from the laboratory data.
When the flux at the bottom of the root zone is considered, both models show a fairly good capability to capture the influence of the shallow water table on the alternation of capillary rise and percolation fluxes at the bottom boundary over the simulation time, regardless of the parameter set. However, the accuracy of the simulated values is generally rather poor. In many cases the patterns simulated by the two models are delayed and smoothened in comparison with the data estimated from measured water balance components. This is particularly true in the case of ALHyMUS, as a consequence of the simplified representation of some of the processes in the soil profile, such as the percolation and the capillary rise. However, it cannot be concluded that ALHyMUS generally performs worse than SWAP, the results depend greatly on the parameter set adopted.

The simulation results show clearly that soil hydraulic parameters obtained with direct methods do not necessarily guarantee the best performance. Indeed, for the specific case of the given experimental profile, the use of PTFs based on site-specific texture and organic matter data did provide comparable results using both of the tested models. It can therefore be stated that, at least for the case study, there is not a single method for the determination of soil hydraulic parameters that is better than the others, and the suitability of a particular method was also dependant on the type of simulation model that was used.

Moreover, the variability of the simulated average soil moisture and of the bottom flux due to the choice of the soil hydraulic parameter values is often larger than the difference between the values of the same output variables simulated by the two models adopting the same parameter set. This demonstrates that for these processes the choice of the method for deriving the values of the soil hydraulic parameters may be more important than the choice of the model.

It is commonly accepted that when the model parameters can be calibrated on the basis of local observations, then physically based models can provide a better performance than conceptual models do. Nevertheless, results of this study show that when the model parameters are derived from either direct or indirect methods, but no site-specific calibration is carried out, the performance of the two types of models can be very similar. In the authors opinion this issue deserves more research, since it could be very important, especially for large scale, spatially distributed model applications.

Finally, we would like to emphasize the need to consider multiple output variables in the evaluation of parameterization methods and of model performances. Evaluation of model performance is often based on the comparison of measured and computed soil moisture patterns (see e.g. Starks et al., 2003). However, this may lead to ambiguous conclusions because a good agreement of soil moisture patterns may occur even if evapotranspiration and flux at the bottom of the soil profile are poorly simulated. This was already highlighted by Cresswell and Paydar (2000) and is confirmed 
by the results provided in this paper. We showed that a good agreement between the computed and observed values of the daily average soil water content in the root zone can be achieved, even if the evapotranspiration is overestimated and fluxes at the bottom of the root zone are underestimated. Clearly the errors in surface and bottom fluxes compensate each other, at least to a certain extent, and cannot be captured by looking just at soil moisture patterns. Therefore, multiple output variables should be considered for the evaluation of various parameterization methods and simulation models.

Acknowledgements. The research was financed by Fondazione CARIPLO and MIUR-PRIN which are gratefully acknowledged. The authors wish to thank Nunzio Romano and his staff (DIAATUniversity of Naples Federico II) for laboratory determinations of soil hydraulic properties and Roberto Comolli (DISAT-University of Milano-Bicocca) for support in soil characterization and sampling. Finally, the authors wish to thank the referees for their thoughtful and constructive comments.

Edited by: W. Durner

\section{References}

Allen, R., Pereira, L. S., Raes, D., and Smith, M.: FAO, Irrigation and drainage Paper 56, Crop evapotranspiration, Guidelines for computing crop water requirements, 1998.

Bastet, G., Bruand, A., Voltz, M., Bornand, M., and Quétin, P.: Performance of available pedotransfer functions for predicting the water retention properties of French soils, in: Characterization and Measurement of the Hydraulic Properties of Unsaturated Porous Media, edited by: van Genuchten, M. T., Leij, F. J., and Wu, L., University of California, Riverside, USA, 981991, 1999.

Belmans, C., Wesseling, J. C., and Feddes, R. A.: Simulation of the water balance of a cropped soil: SWATRE, J. Hydrol., 63, 271-286, 1983.

Borgarello, M., Catenacci, G., Cavicchioli, C., and Parini, S.: Indagini sulla deposizione secca, Rapporto CISE-SAA-93-042, CISE, Milano, 1993.

Bouma, J.: Using soil survey data for quantitative land evaluation. Adv. Soil Sci., 9, 177-213, 1989.

Bouma, J. and van Lanen, J. A. J.: Transfer functions and threshold values; from soil characteristics to land qualities, in: Quantified Land Evaluation, edited by: Beek, K. J., Burrough, P. A., and McCormack, D. E., International Institute Aerospace Survey Earth Science, ITC Publishing, Enschede, The Netherlands, 106-110, 1987.

Bouraoui F. and Dillaha T. A.: ANSWERS-2000: Runoff and sediment transport model, J. Environ. Eng., 6, 493-502, 1996.

Braden, H.: Ein Energiehaushalts- und Verdunstungsmodell für Wasser- und Stoffhaushaltsuntersuchungen landwirtschaftlich genutzer Einzugsgebiete, Mitteilungen der Deutschen Bodenkundlichen Gesellschaft, 42, 294-299, 1985.
Christiaens, K. and Feyen, J.: Analysis of uncertainties associated with different methods to determine soil hydraulic properties and their propagation in the distributed hydrological MIKE SHE model, J. Hydrol., 246, 63-81, 2001.

Coppola, A., Basile, A., Comegna, A., and Lamaddalena, N.: Monte Carlo analysis of field water flow comparing uni and bimodal effective hydraulic parameters for structured soil, J. Contam. Hydrol., 104(1-4), 153-165, 2009.

Cosby, B. J., Hornberger, G. M., Clapp, R. B., and Ginn, T. R.: A statistical exploration of the relationship of soil moisture characteristics to the physical properties of soils, Water Resour. Res., 20, 682-690, 1984.

Cresswell, H. P. and Paydar, Z.: Functional evaluation of methods for predicting the soil water characteristic, J. Hydrol., 227, 160 $172,2000$.

D’Urso, G. and Basile, A.: Physico-empirical approach for mapping soil hydraulic behaviour, Hydrol. Earth Syst. Sci., 1, 915923, 1997, http://www.hydrol-earth-syst-sci.net/1/915/1997/.

Eitzinger, J., Trnka, M., Hosch, J., Alud, Z., and Dubrovsky, M.: Comparison of CERES, WOFOST and SWAP models in simulating soil water content during growing season under different soil conditions, Ecol. Model., 171, 223-246, 2004.

ERSAL (Ente Regionale Sviluppo Agricolo Lombardo), Progetto carta pedologica - I suoli della pianura pavese centrale, Regione Lombardia, 2001.

Facchi, A., Ortuani, B., Maggi, D., and Gandolfi, C.: Coupled SVAT-groundwater model for water resources simulation in irrigated alluvial plains, Environ. Modell. Softw., 19(11), 10531063, 2004.

Flanagan, D. C. and Livingston, S. J.: WEPP User Summary, NSERL Report No. 11., National Soil Erosion Research Laboratory, West Lafayette, 131 pp., 1995.

Freeze, R. A. and Cherry, J. A.: Groundwater, Prentice Hall Inc., Englewood Cliffs, New Jersey, 604 pp., 1979.

Gandolfi, C., Facchi, A., and Maggi, D.: Comparison of 1D models of water flow in unsaturated soils, Environ. Modell. Softw., 21, 1759-1764, 2006.

Gerosa, G., Cieslik, S., and Ballarin-Denti, A.: Micrometeorological determination of time integrated stomatal ozone fluxes over wheat: a case study in Northern Italy, Atm. Environm., 37(6), 777-788(C), 2003.

Gijsman, A. J., Jagtap, S. S., and Jones, J. W.: Wading through a swamp of complete confusion: how to choose a method for estimating soil water retention parameters for crop models, Europ. J. Agronomy, 18, 77-106, 2003.

Goudriaan, J.: Crop meteorology: a simulation study, Simulation monographs, Pudoc, Wageningen, The Netherlands, 1977.

Green, W. H. and Ampt, G.: Studies of soil physics. Part I. The flow of air and water through soils, J. Agr. Sci, 4, 1-24, 1911.

Guber, A. K., Pachepsky, Y. A., van Genuchten, M. Th., Šimnek, J., Jacques, D., Nemes, A. , Nicholson, T. J., and Cady, R. E.: Multimodel simulation of water flow in a field soil using pedotransfer functions, Vadose Zone J., 8(1), 1-10, 2009.

Gupta, S. C. and Larson, W. E.: Estimating soil water retention characteristics from particle size distribution, organic matter percent, and bulk density, Water Resour. Res., 15, 1633-1635, 1979. 
Guswa, A. J., Celia, M. A., and Rodriguez-Iturbe, I.: Models of soil moisture dynamics in ecohydrology: a comparative study, Water Resour. Res., 38(2), 1-15, 2002.

Haverkamp, R., Debionne, S., Viallet, P., Angulo-Jaramillo, R., and de Condappa, D.: Soil Properties and Moisture Movement in the Unsaturated zone, in: Handbook of Groundwater Engineering, The Second Edition, edited by: Delleur, J. W., Springer, Heidelberg, 2006.

Herbst, M., Fialkiewicz, W., Chen, T., Putz, T., Thiéry, D., Mouvet, C., Vachaud, G., and Vereecken, H.: Intercomparison of Flow and Transport Models Applied to Vertical Drainage in Cropped Lysimeters, Vadose Zone J., 4, 240-254, 2005.

Hupet, F., van Dam, J. C., and Vanclooster, M.: Impact of withinfield variability in soil hydraulic properties on transpiration fluxes and crop yields: a numerical study, Vadose Zone J., 3, 1367-1379, 2004.

Huygen, J. C., van Dam, J. C., Kroes, J. G., and Wesseling, J. G.: SWAP 2.0: input and output manual, Technical document, WAU and DLO-Staring Centrum, Wageningen, 1997.

Islam, N., Wallender, W. W., Mitchell, J. P., Wicks, S., and Howitt, R. E.: Performance evaluation of methods for the estimation of soil hydraulic parameters and their suitability in a hydrologic model, Geoderma, 134, 135-151, 2006.

Jeffrey, D. W.: A note on the use of ignition loss as a means for the approximate estimation of soil bulk density, J. Ecology, 58, 297-299, 1970.

Johnson, H. and Jansson, P. E.: Water balance and soil moisture dynamics of field plots with barley and grass ley, J. Hydrol., 129, 149-173, 1991.

Johrar, R. K., van Dam, J. C., Bastiaansan, W. G. M., and Feddes, R. A.: Calibration of effective soil hydraulic parameters of heterogeneous soil profiles, J. Hydrol., 285, 233-247, 2004.

Kroes, J. G. and van Dam, J. C.: Reference Manual SWAP version 3.0.3, Alterra-rapport 773, ISSN 1566-7197, 2003.

Lamorski, K., Pachepsky, Y., Slawinski, C., and Walczak, R. T.: Using Support Vector Machines to Develop Pedotransfer Functions for Water Retention of Soils in Poland, Soil Sci. Soc. Am. J., 72, 1243-1247, 2008.

Leij, F. J., Alves, W. J., van Genuchten, M. Th., and Williams, J. R.: The UNSODA-Unsaturated Soil Hydraulic Database. User's manual Version 1.0. Report EPA/600/R-96/095, National Risk Management Research Laboratory, Office of Research and Development, US Environmental Protection Agency, Cincinnati, $\mathrm{OH}, 1996$.

Liu, Y., Pereira, L. S., and Fernando, R. M.: Fluxes through the bottom boundary of the root zone in silty soils: parametric approaches to estimate groundwater contribution and percolation, Agric. Water Manag., 84, 27-40, 2006.

Maraux, F., Lafolie, F., and Bruckler, L.: Comparison between mechanistic and functional models for estimating soil water balance: deterministic and stochastic approaches, Agric. Water Manag., 38, 1-20, 1998.

Minansy, B. and McBratney, A. B.: The Neur-N method for fitting neural network parametric pedotransfer functions, Soil Sci. Soc. Am. J., 66, 352-361, 2002.

Monteith, J. L.: Evaporation and the Environment, in: The state and movement of water in living organisms, edited by: Fogg, G. E., Cambridge University Press, 205-234, 1965.
Mualem, Y.: A new model for predicting the hydraulic conductivity of unsaturated porous media, Water Resour. Res., 12, 513-522, 1976.

Neitsch, S., Arnold, J., Kiniry, J., Srinivasan, R., and Williams, J.: Soil and water assessment tool users manual version 2000, GSWRL report 02-02, BRC report 02-06, Texas Water Resources Institute, College Station, TX, 2002.

Nemes, A., Schaap, M. G., and Wösten, J. H. M.: Functional evaluation of pedotransfer functions derived from different scales of data collection, Soil Sci. Soc. Am. J., 67, 1093-1102, 2003.

Nemes, A., Wosten, J. H. M., Bouma, J., and Varallyay, G.: Soil water balance scenario studies using predicted soil hydraulic parameters, Hydr. Proc., 20, 1075-1094, 2006 a.

Nemes, A., Rawls, W. J., and Pachepsky, Y. A.: Use of the Nonparametric Nearest Neighbor Approach to Estimate Soil Hydraulic Properties, Soil Sci. Soc. Am. J., 70, 327-336, 2006 b.

Nemes, A., Rawls, W. J., Pachepsky, Y. A., and van Genuchten, M. Th.: Sensitivity Analysis of the Nonparametric Nearest Neighbor Technique to Estimate Soil Water Retention, Vadose Zone J., 5, 1222-1235, 2006c.

Niswonger, R., Prudic, D., and Regan, R.: Documentation of the unsaturated zone flow (UZF1) package for modeling unsaturated flow between the land surface and the water table with MODFLOW, Tech. Meth. 6-A19, USGS, 965 Reston, VA, 2006.

Pachepsky, Y. A. and Rawls, W. J.: Accuracy and reliability of pedotransfer function as affected by grouping soils, Soil Sci. Soc. Am. J., 63, 1748-1757, 1999.

Pachepsky, Y. A., Smettem, K. R. J., Vanderborght, J., Herbst, M., Vereecken, H., and Wösten, J. H. M.: Reality and fiction of models and data in soil hydrology, in: Unsaturated-Zone Modelling, edited by: Feddes, R. A., de Rooij, G. H., and van Dam, J. C., Kluwer Academic Publishers, Dordrecht, The Nederlands, 2004.

Rawls, W. J. and Brakensiek, D. L.: Estimation of soil water retention and hydraulic properties, in: Unsaturated flow in hydrologic modelling, Theory and Practice, edited by: Morel-Seytoux, H. J., Kluwer Academic Publishers, 275-300, 1989.

Refsgaard, J. C. and Storm, B.: MIKE SHE, in: Computer models of watershed hydrology, edited by: Singh, V. P., Water Resour, Publ., Littleton, CO, 809-846, 1995.

Reynolds, W. D., Elrick, D. E., Youngs, G., Booltink, H. W. G., and Bouma, J.: Saturated and field-saturated water flow parameters: laboratory methods, in: Methods of Soil Analysis, Part 4, 2002.

Romano, N., Hopmans, J. W., and Dane, J. H.: Water retention and storage: Suction table, in: Methods of Soil Analysis, Part 4, Physical Methods, edited by: Dane, J. H. and Topp, G. C., SSSA Book Series N.5, Madison, WI, USA, ISBN 0-89118-841X, 692-698, 2002.

Richards, L. A.: Capillary conduction of liquids through porous mediums, Physics, 1, 318-333, 1931.

Romano, N.: Water retention and movement in the soil, in: CGIR Handbook of Agricultural Engineering, ASAE, 1999.

Saxton, K. E. and Rawls, W. J.: Soil water characteristic estimates by texture and organic matter for hydrologic solutions, Soil Sci. Soc. Am. J., 70, 1569-1578, 2006.

Schaap, M. G., Leij, F. J., and van Genuchten, M. Th.: ROSETTA: A computer program for estimating soil hydraulic parameters with hierarchical pedotransfer functions, J. Hydrol., 251, 163176, 2001. 
Schulla, J. and Jasper, K.: Model DescriptionWaSiM-ETH. Internal report, IAC, ETH Zurich, 166 pp., 2001.

Sharpley, A. N. and Williams, J. R.: EPIC Erosion Productivity Impact Calculator: 1. Model documentation, ARS-31, USDA, 1990.

Simunek, J., Huang, K., and van Genuchten, M. Th.: The HYDRUS Code, Research Report No. 144, US Salinity Laboratory Agricultural Research Service, USDA, Riverside, California, 1998.

Soet, M. and Stricker, J. N. M.: Functional behaviour of pedotransfer functions in soil water flow simulation, Hydrol. Process., 17, 1659-1670, 2003.

Starks, P. J., Heathman, G. C., Ahuja, L. R., and Ma, L.: Use of limited soil property data and modeling to estimate root zone soil water content, J. Hydrol., 272, 131-147, 2003.

Stoppelenburg, F. J., Kovar, K., Pastoors, M. J. H., and Tiktak, A.: Modeling the interactions between transient saturated and unsaturated groundwater flow. Off -line coupling of LGM and SWAP, Rep. 500026001, RIVM, Bilthoven, The Netherlands, 2005.

Strudley, M. W., Green, T. R., and Ascough, J. C.: Tillage effects on soil hydraulic properties in space and time: state of the science, Soil Till. Res., 99, 4-48, 2008.

Sudicky, E. A., Park, Y. J., Unger, A. J. A., Jones, J. P., Brookfield, A. E., Colautti, D., Therrien, R., and Graft, T.: Simulating complex flow and contaminant transport dynamics in an integrated surface-subsurface modeling framework., in GSA Annu. Meet. and Exposition, Philadephia, Geol. Soc. of Am., Boulder, CO, 38(7), p. 258, 2006.

Tietje, O. and Hennings, V.: Accuracy of the saturated hydraulics conductivity prediction by pedo-transfer function compared to the variability within FAO textural classes, Geoderma, 69, 7184, 1996.

Tietje, O. and Tapkenhinrichs, M.: Evaluation of pedo-transfer functions, Soil Sci. Soc. Am. J., 57, 1088-1095, 1993.

Twarakavi, N. K. C., Simunek, J., and Schaap, M. G.: Development of Pedotransfer Functions for Estimation of Soil Hydraulic Parameters using Support Vector Machines, Soil Sci. Soc. Am. J., 73, 1443-1452, 2009.

Ungaro, F. and Calzolari, C., Using existing soil databases for estimating retention properties for soils of the Pianura PadanoVeneta region of North Italy, Geoderma, 99, 99-121, 2001.

Ungaro, F., Calzolari, C., and Busoni, E.: Development of pedotransfer functions using a group method of data handling for the soil of the Pianura Padano-Veneta region of North Italy: water retention properties, Geoderma, 124, 293-317, 2005. van Dam, J. C., Huygen, J., Wesseling, J. G., Feddes, R. A., Kabat, P., Van Walsum, P. E. V., Groenendijk, P., and Van Diepen, C. A.: Theory of SWAP version 2.0. Simulation of water flow, solute transport and plant growth in the Soil-Water-AtmospherePlant environment, Report 71, Department of Water Resources, WAU, Technical Document 45, DLO Winand Staring CentreDLO, 167 pp., 1997.

van Dam, J. C., Groenendijk, P., Hendriks, R. F. A., and Kroes, J. G.: Advances of Modeling Water Flow in Variably Saturated Soils with SWAP, Vadoze Zone J., 7, 640-653, 2008.

van Genuchten, M. Th.: A closed form equation for predicting the hydraulic conductivity of unsaturated soils, Soil Sci. Soc. Am. J., 44, 892-898, 1980.

van Genuchten, M. Th., Leij, F. J., and Yates, S. R.: The RETC code for quantifying the hydraulic functions of unsaturated soils, USEPA Rep. IAG-DW12933934, R.S. Kerr Environ. Res. Lab., US Environmental Protection Agency, Ada, OK, USA, 1991.

Vereecken, H., Diels, J., van Orshoven, J., Feyen, J., and Bouma, J.: Functional evaluation of pedotransfer functions for the estimation of soil hydraulic properties, Soil. Sci. Soc. Am. J., 56, 1371-1378, 1992.

Vereecken, H., Maes, J., and Darius, P.: Estimating the soil moisture retention characteristic from texture, bulk density and carbon content, Soil Sci., 148, 389-403, 1989.

Workmann, S. R. and Skaggs, R. W.: Sensitivity of water management models to approaches for determining soil hydraulic properties, Transaction of the ASAE, 37(1), 95-102, 1994.

Wösten, J. H. M., Bannink, M. H., de Gruijter, J. J., and Bouma, J.: A procedure to identify different groups of hydraulic conductivity and moisture retention curves for soil horizons, J. Hydrol., 86, 133-145, 1986.

Wösten, J. H. M., Lilly, A., Nemes, A., and Le Bas, C.: Development and use of a database of hydraulic properties of european soils, Geoderma, 90, 169-185, 1999.

Wösten, J. H. M., Pachepsky, Ya. A., and Rawls, W. J.: Pedotransfer functions: bridging the gap between available basic soil data and missing soil hydraulic characteristics, J. Hydrol, 251, 123-150, 2001. 